\title{
Glossary and Acronyms
}

Actinic flux or radiation This is the solar flux used in calculating photodissociation rates, corresponding to the mean intensity at a given point in the atmosphere.

Adaptive optics A new observational technique where the phase perturbations induced by the Earth's atmospheric turbulence, responsible for the blur in the images recovered, is corrected in real time on the incident wavefront reaching the telescope. These perturbations are measured by a wavefront sensor. Opposite phase corrections are then applied using a thin deformable mirror in the pupil plane.

Adiabatic Lapse Rate The lapse rate is the drop of temperature with altitude. Frequently this quantity is close or equal to that for a parcel of air moving without transfer of energy ('adiabatic'). As a parcel moves upwards, it expands as the atmospheric pressure falls. The expansion requires work to be done, this work coming from the internal energy of the air parcel. Thus the parcel cools as it rises.

Albedo Albedo is a ratio of scattered to incident electromagnetic radiation power, most commonly light. It is a unitless measure of a surface or body's reflectivity. The geometric albedo of an astronomical body is the ratio of its total brightness at zero phase angle to that of an idealised fully reflecting, diffusively scattering (Lambertian) disk with the same cross-section. Zero phase angle corresponds to looking along the direction of illumination. For Earth-bound observers, this occurs when the body in question is at opposition. The visual geometric albedo refers to this quantity when calculated taking into account only electromagnetic radiation in the visual range. The Bond albedo is the fraction of power in the total electromagnetic radiation incident on an astronomical body that is scattered back out into space. This takes into account all wavelengths. It is an important quantity for characterising a planetary body's energy balance. For objects in the solar system, the main contribution comes from visible light because the majority of solar output is in this range. The Bond albedo $(A)$ is related to the geometric albedo $(p)$ by the expression $A=p q$, where $(q)$ is termed the phase integral.

AMU Atomic mass unit, defined so that the mass of the commonest carbon isotope is $12 \mathrm{amu}$, making the mass of the hydrogen atom approximately equal to $1 \mathrm{amu}$.

Apoapsis The point on an orbit when the spacecraft is furthest from the planet it is orbiting. 
Arcmin An arc minute, or minute of arc. An angle equal to one-sixtieth of a degree, or sixty arc-seconds. The field of view of the Hubble Space Telescope Planetary Camera is $34 \times 34$ arc seconds. Titan as seen from Earth subtends an angle of about 1 arc-second.

Astronomical Unit (AU) The mean distance of the Earth from the Sun, or about 150 million kilometres.

\begin{abstract}
Atmospheric layers By analogy with the Earth, Titan's atmosphere is subdivided into layers defined by the temperature variations with height (or pressure, through the hydrostatic law). On both Titan and the Earth, the mean temperature profile is characterised by two temperature inversions (locations above which the temperature increases with altitude, while the opposite takes place beneath). The boundaries between regions are identified by terms ending with -pause (from the Greek $\pi \alpha v \sigma \eta \varsigma$ meaning end).
\end{abstract}

Bar A unit of pressure, defined to be equal to $10^{5}$ pascals (Pa). The mean surface pressure of the Earth (often called one atmosphere) is approximately 1 bar (actually $1.01325 \times 10^{5}$ pascals). Atmospheric pressures are often quoted in millibars (mbar). $1 \mathrm{bar}$ is also equal to $1,000,000$ dynes per square centimetre; $1 \mathrm{mbar}=0.001$ bar $=100 \mathrm{~Pa}=1,000 \mathrm{dyn} / \mathrm{cm}^{2}$.

Baroclinic, barotropic Barotropic is a region of uniform temperature distribution; a lack of fronts. Everyday being similar (hot and humid with no cold fronts to cool things off) would be a barotropic type atmosphere, as we find at tropical latitudes. In a baroclinic region, on the other hand, distinct air mass regions exist. Fronts separate warmer from colder air. In a synoptic scale baroclinic environment, you will find the polar jet in the vicinity, troughs of low pressure (mid-latitude cyclones) and frontal boundaries. There are clear density gradients in a baroclinic environment caused by the fronts. Any time you are near a mid-latitude cyclone, you are in a baroclinic environment.

Central Meridian The longitude of the horizontal center of a coordinate system. This longitude value is often the longitude origin of the coordinate system, or the chosen meridian plane from which longitude is measured. On Earth, the central, or zero meridian, is commonly accepted since 1884 as the Greenwich Meridian, which runs through Greenwich, England. On Titan, the Eastern Elongation corresponds to $90^{\circ}$ Longitude of the Central Meridian - LCM — as opposed to geographical longitude, which is about $210^{\circ}$, since Titan rotates synchronously with Saturn.

Clathrate A clathrate or clathrate compound or cage compound is a chemical substance consisting of a lattice of one type of molecule trapping and containing a second type of molecule. A clathrate therefore is a material which is a weak 
composite, with molecules of suitable size captured in spaces which are left by the other compounds.

Cryovolcanism Cryovolcanism is the existence of cryovolcanoes and their effects. A cryovolcano is, literally, an icy volcano. Cryovolcanoes form on icy moons, and possibly on other low temperature astronomical objects (e.g. Kuiper belt objects). Rather than molten rock, these volcanoes erupt volatiles such as water, ammonia or methane. Collectively referred to as cryomagma or ice-volcanic melt, these substances are usually liquids and form flumes, but can also be in vapour form. After eruption, cryomagma condenses to a solid form when exposed to the very low surrounding temperature. The Cassini-Huygens mission has found cryovolcanism on Enceladus and a methane-spewing cryovolcano on Titan, and such volcanism is now believed to be a significant source of the methane found in Titan's atmosphere.

Collision-induced absorption Absorption bands of molecules which occur because collisions between molecules induce dipole moments which are not otherwise present. On Titan, collisions between $\mathrm{CH}_{4}$ and $\mathrm{N}_{2}$ (in every combination) make an important contribution to the opacity of the atmosphere at middle and long infrared wavelengths and moderate to low altitudes.

Cyclostrophic balance On Earth, the surface rotation typically surpasses the zonal winds, and the pressure gradient force generated by the unequal solar fluxes at low and high latitudes is balanced by the Coriolis force, in what is called a "geostrophic balance". On Titan (and Venus) the opposite is true, and pressure gradients are balanced by strong centrifugal forces arising from the rapid rotation of the atmosphere. This balance, typical of cyclones, is called cyclostrophic.

Dayglow A fluorescent emission of radiation from the upper atmosphere, due to excitation by high-energy sunlight photons.

Deuterium The heavy isotope of hydrogen, with a proton and neutron in its atomic nucleus. Deuterium (and hydrogen compounds like methane and water) participates in chemical reactions and physical processes such as diffusion and evaporation at different rates from normal hydrogen. The deuterium to hydrogen ratio $(\mathrm{D} / \mathrm{H})$ in an atmosphere is therefore an indicator of the separation processes that have occurred in it.

Dynamical inertia The increase in radiative time constant due to mixing of more massive deeper layers of an atmosphere. The thin atmosphere at high altitudes would be expected to respond rapidly to changes in sunlight, but if there is substantial vertical circulation, the changes will occur more slowly as the mixing increases the effective mass of the layer under consideration. 
Eccentricity The eccentricity of this conic section, the orbit's eccentricity, is an important parameter of the orbit that defines its absolute shape. Eccentricity may be interpreted as a measure of how much this shape deviates from a circle. Under standard assumptions, eccentricity $(e)$ is strictly defined for all circular, elliptic, parabolic and hyperbolic orbits (for a circular orbit, the eccentricity is 0 ).

Exobiology The study of life beyond the Earth. More broadly, the term encompasses study of environments favourable for life, the origin and evolution of life in the universe, and the evolution of intelligence and technology.

Exosphere The outermost part of the atmosphere, extending to outer space from about $1,500 \mathrm{~km}$ altitude on Titan, where light elements, especially hydrogen, can escape the planet's grip and are lost to space.

Geometric Albedo The ratio of the total reflected flux in all directions by a planet to the incident solar flux received by a sphere of unit radius, divided by the phase integral. For a highly reflecting atmosphere or surface, the geometric albedo is in the range $0.65-0.80$, depending on the phase function.

\section{HST Hubble Space Telescope.}

Hadley circulation A meridional (North-South) flow pattern in the atmosphere, transporting heat away from warmer to colder regions, which on the Earth rises at low latitudes and descends at high latitudes.

Homopause A fairly small distance up into the thermosphere, diffusion takes over as the dominant process and the atmosphere starts to separate into its lighter and heavier components. For many practical purposes, this level (the homopause) may be considered to be the effective top of the atmosphere.

Ionosphere The region of a planetary atmosphere where charged particles, ions and electrons, are present in significant numbers. The ionosphere is usually a lowdensity region; on Titan, its peak occurs roughly 1,000 km above the surface.

Infrared spectroscopy The dispersal and measurement of infrared light intensity. Near-infrared (0.7 to 5 microns) spectroscopy is useful for mineral and ice identification; mid-infrared (5 to 30 microns) is more useful for measuring surface temperatures, and measuring gas abundances.

IRIS The Infrared Interferometer Spectrometer, an instrument on the Voyager missions. See Chapter 2.

ISO The Infrared Space Observatory. See Chapter 3. 
Jeans escape The process by which fast (energetic, or hot) molecules of an atmosphere escape into space. The energy distribution of a gas at a given temperature has a hot tail - a few atoms moving faster than the rest. Therefore if, at an altitude where collisions between molecules are rare, the molecules in the hot tail move faster than the local escape velocity, they can escape to space. This process is fastest for hot atmospheres of light gases (hydrogen, helium) on bodies with low gravity.

Limb-darkening The darkening of the edges of a planetary disk. This may be due to the scattering properties of the surface (if, for example, it is a strongly backscattering surface, like an icy one), or more usually to the presence of an optically thick atmosphere. It is often characterised by an exponent $k$, the Minnaert exponent, for a scattering law of the form $I=I 0 \mu k \mu \mathrm{o} k-1$, where $\mu$ and $\mu \mathrm{o}$ are the cosines of the angle between the normal at a given point and the observer and Sun respectively and Io is the brightness of the centre of the disk. $k=0.5$ corresponds to a flat disk (rather like the moon), while $k=1$ is a Lambertian disk with strong limb-darkening. $k<0.5$ corresponds to limb-brightening, typical of a scattering but optically thin region above an absorbing (dark) region in the atmosphere.

Mesosphere Above the stratopause, the temperature declines again, reaching a minimum at the mesopause, where the second temperature inversion occurs, signifying the end of the mesosphere. The pressure at the mesopause is about one microbar on Titan, and occurs approximately $600 \mathrm{~km}$ above the surface.

Micron (or micrometre) A micrometre (symbol $\mu \mathrm{m}$ ) is one millionth of a metre.

Mixing ratio The fraction of the total volume due to a given compound. Also expressed as a column abundance (m-amagat).

Mixing ratio scale height If the mixing ratio of a given compound in an atmosphere changes with altitude, due to its production or removal at given altitudes, its variation may be conveniently described by a function of the form $\exp (-h / H)$, where $\mathrm{h}$ is the change in altitude and $H$ is the mixing ratio scale height, the vertical distance over which the mixing ratio changes by a factor $e$.

Oblateness The flattening of a planet or satellite, usually due at least in part to its spin. The oblateness is the difference between the polar and equatorial radii, divided by the equatorial radius. The Earth's oblateness is 1/298; Titan's atmosphere has an oblateness of about $1 / 250$ at an altitude of $250 \mathrm{~km}$, from which the rapid rotation of the upper atmosphere has been inferred.

Obliquity The tilt of a planet's axis of rotation, relative to the direction perpendicular to the ecliptic plane (the plane containing the Sun's equator and the orbits of most of the planets). A planet with near-zero obliquity, like Venus, has no seasons. The obliquity of Saturn is 26.4 degrees, so Titan has significant seasons. 
Opacity The ability of an atmosphere to absorb (or sometimes scatter) radiation. Also called optical depth. A beam of monochromatic radiation passing through an atmosphere with an optical depth of one will have its intensity reduced by a factor $e(=2.718 \cdots)$, while an optical depth of 4 absorbs $99 \%$ of the radiation. Opacity is a function of wavelength as well as the pressure, temperature and composition of the region of the atmosphere under consideration.

Optical depth A measure of how opaque a layer of atmospheric gas or cloud is, defined as the logarithm of the transmission. It can take values from 0 (perfectly transparent) to infinity (perfectly opaque), and is of course a function of wavelength.

Optically thin Absorbing or scattering relatively little radiation, i.e. 'clear'. The usual interpretation of this term is that the optical depth is less than one.

Periapsis The point on an orbit when the spacecraft is closest to the planet it is orbiting.

Phase angle The phase angle is the angle between the incoming and outgoing beams. High phase angle observations are those in which the incident and scattered rays are almost in a straight line, i.e. forward scattering or grazing incidence. Because Titan is so far from the Sun, the illumination always comes from behind an observer on or near the Earth, so she sees only backscattered rays. High phase angle observations are only obtainable from a spacecraft passing around the other side of Titan.

Phase function The phase function is the mathematical expression which describes the distribution of scattered light from an object, as a function of phase angle. It can be analysed in terms of the optical properties (refractive index) and microphysics (particle size and shape, or surface roughness) of the medium doing the scattering, which on Titan is the high-level haze in the visible, plus a contribution from the surface at longer wavelengths.

Photolysis The breaking of a chemical bond by a light photon (usually at ultraviolet wavelengths). The molecular fragments may recombine in a number of ways. Among easily-photolysed gases are methane, ammonia and oxygen, but even 'unreactive' gases such as nitrogen may react photochemically to produce other compounds (such as HCN on Titan, or nitrogen oxides on Earth).

Prebiotic Molecules or conditions which are thought to have been necessary or likely precursors for the processes which led to the origins of life on Earth.

Radio-occultation The passing of a radio beam through a planet's atmosphere. Attenuation and refraction (bending) of the beam - generally by phase delay can be used to measure the density of electrons in the planets ionosphere, and the 
density of the gas in its atmosphere. The abrupt cut-off of the signal can also be used to make a precise measurement of the planet's surface radius.

Remote sensing The determination of atmospheric and surface properties by measurement and analysis of emitted or reflected radiation, usually at infrared or longer (microwave, radio) wavelengths.

Scale height The vertical distance over which atmospheric pressure changes by a factor $e$. The property is described by a function of the form $\exp (-h / H)$, where $h$ is the change in altitude and $H$ is the scale height. Four scale heights above the surface, the pressure is about $1 / 100$ of its surface value. For an isothermal atmosphere, the pressure scale height is equal to $(R T / g)$, where $g$ is the local gravity, $R$ the gas constant appropriate to the atmospheric composition and $T$ the local temperature in $\mathrm{K}$. As all of these quantities vary with altitude, the scale height also varies with altitude, but it is often a convenient approximation to assume it to be constant. For the Earth, the scale height is around $10 \mathrm{~km}$, while for Titan's upper atmosphere, the value is nearer $40 \mathrm{~km}$.

Stratosphere The stratosphere is the region where each layer is heated by radiation from the optically thick atmosphere below, and cooled by radiating to space; here density decreases monotonically with height, and therefore the layers do not try to move up or down through each other as in the troposphere. The temperature is also maximum at the upper boundary, which is known as the stratopause, due to the absorption and conversion of UV solar radiation by different gases and aerosols. Titan's stratosphere lies between about 50 and $250 \mathrm{~km}$ altitude (roughly 100 to 0.1 mbar pressure).

Super-rotation The rapid (prograde) rotation of the upper layers of the atmosphere, notable in both Venus and Titan. The atmosphere of Titan at a few hundred kilometres altitude may make around twenty revolutions for every revolution Titan's solid body makes.

Scale height The vertical distance over which an atmospheric property (usually pressure, or density) changes by a factor $e$. The property is described by a function of the form $\exp (-h / H)$, where $h$ is the change in altitude and $H$ is the scale height. Four scale heights above the surface, the pressure is about $1 / 100$ of its surface value. For an isothermal atmosphere, the pressure scale height is equal to $\left(c_{p} T / g M\right)$, where $g$ is the local gravity, $M$ the relative molecular mass, $c_{p}$ the specific heat at constant pressure and $T$ the local temperature in $\mathrm{K}$. As all of these quantities vary with altitude, the scale height also varies with altitude, but it is often a convenient approximation to assume it to be constant. For the Earth, the scale height is around $10 \mathrm{~km}$, while for Titan's upper atmosphere, the value is nearer $40 \mathrm{~km}$. 
Thermosphere With such low densities of gas above, very energetic solar photons in the extreme ultraviolet, and particles too, penetrate into the region causing ionisation and dissociation and releasing kinetic energy. The heating thus produced causes the temperature to increase rapidly with height, leading to the name thermosphere $(\theta \varepsilon \rho \mu o=$ warm $)$, the most extensive part of the atmosphere, in which the energy is transported by thermal conduction.

Terminator The boundary between day and night on a planet.

Troposphere Convective instability exists in the lowest $40 \mathrm{~km}$ or so of the atmosphere (that is to say that since the temperature decreases with altitude, the warmer air lying under colder air is unstable and so it rises while the colder air sinks), which is known as the troposphere ('turning-region'). The upper boundary here is the level where the overlying atmosphere is of such a low density that a substantial amount of radiative cooling to space can occur in the thermal infrared region of the spectrum. At this level, called the tropopause, radiation cools rising air so efficiently that the temperature tends to become constant with height and convection ceases.

Wavenumber, wavelength Often expressed also as a wavenumber (e.g. a wavenumber of $10,000 \mathrm{~cm}^{-1}$ indicates 10,000 wavelengths fit into one centimetre, so the wavelength is 1 micron. A wavelength of 10 microns therefore has a wavenumber of $1,000 \mathrm{~cm}^{-1}$.) Wavenumber is the spatial analogue of angular frequency. In spectroscopy, the wavenumber $\mathrm{n}$ of electromagnetic radiation is defined as $v=1 / l$, where $\lambda$ as a length in the SI-system is measured in meters (m) and commonly quantified in centimetres $\left(\mathrm{cm}=10^{-2} \mathrm{~m}\right)$ refers to the wavelength in vacuum. The unit of this quantity is $\mathrm{cm}^{-1}$, pronounced as reciprocal centimetre, or "inverse centimetre".

Window A spectral region which is relatively transparent, between two regions which have higher opacity. A window region can be important for remote sensing of a planetary surface, and for limiting the extent of a greenhouse effect. 
Several articles in Science and Nature issues of 2004 and 2005 describe in detail the Cassini-Huygens mission findings. We recommend in particular: Science 307, No. 5713, 25 February 2005, "Cassini arrives at Saturn"; Nature 10 March 2005 "Imaging of Titan from the Cassini spacecraft"; Nature December 8, 2005, all the papers from the first Huygens results. Also: Geophysical Research Letters Vols. 32 and 33, Icarus Vols. 173 and 182-183 and 186, Nature Vols. 438 and 442, Journal of Geophysical Research Vol. 111, Science Vols. 308 and 310; Earth Moon and Planets Vol. 96; Planetary and Space Sciences Vols. 47, 49, 53 and 54; Space Science Reviews Vols. 114 and 115; Advances in Space Research Vols. 26, 28, 33 and $\mathbf{3 6}$.

Volume 104 of Space Science Reviews includes articles with descriptions of the Huygens instruments and the mission in general, plus articles by the Huygens Interdisciplinary Scientists.

\section{Books}

Recent books published in relation to Titan include:

Coustenis, A., Taylor, F., 1999. Titan: the Earth-like Moon, World Scientific Publishers, Singapore. Lorenz, R. D., Mitton, J., 2002. Lifting Titan's Veil: Exploring the Giant Moon of Saturn, Cambridge University Press.

Lunine, J. I., 2004. Astrobiology: Multi Disciplinary Approach. B. Cummings, Publ., ISBN: 0805380426.

Encrenaz, T., Kallenbach, R., Owen, T. C. and Sotin, C., eds., 2005, The Outer Planets and Their Moons. Space Science Series of ISSI, Vol. 19, Springer.

\section{Web sites}

http://www.nasa.gov/mission_pages/cassini/main/index.html http://www.spaceflightnow.com/cassini/ http://saturn.jpl.nasa.gov/multimedia/images/index.cfm http://www.esa.int/SPECIALS/Cassini-Huygens/ http://solarviews.com/cap/index/spacecraft-cassini1.html http://cisas.unipd.it/hasi/welcome.html http://filer.case.edu/ sjr16/advanced/saturn_moons.html http://spaceplace.nasa.gov/en/kids/sse_flipflop2.shtml http://www.aero.jussieu.fr/experience/ACP/ http://www.astro.uni-bonn.de/ dwe/ http://www.esa.int/export/esaSC/120378_index_0_m.html http://www.planetary.org/explore/topics/our_solar_system/saturn/ http://ssd.jpl.nasa.gov/?sat_phys_par 
http://www.lesia.obspm.fr/cosmicvision/tandem/index.php

http://www.lpi.usra.edu/opag/announcements.html

\section{Other References}

Hereafter some significant references on Titan with emphasis on recently published papers (mainly since 2000).

Abbott, A., 2005. Titan team claims just deserts as probe hits moon of crème brûlée. Nature 433, 181. Achterberg, R. K., Conrath, B. J., Gierasch, P. J., Flasar, F. M., Nixon, C. A., 2008. Titan's middleatmospheric temperatures and dynamics observed by the Cassini Composite Infrared Spectrometer. Icarus 194, 263-277.

Ádámkovics, M., de Pater, I., Roe, H. G., Gibbard, S. G., Griffith, C. A., 2004. Spatially-resolved spectroscopy at $1.6 \mu \mathrm{m}$ of Titan's atmosphere and surface. Geophys. Res. Let. 31, CiteID L17S05.

Ádámkovics, M., de Pater, I., Hartung, M., Eisenhauer, F., Genzel, R., Griffith, C. A., 2006. Titan's bright spots: Multiband spectroscopic measurement of surface diversity and hazes. J. Geophys. Res. 111, CiteID E07S06.

Adriani, A., Moriconi, M. L., Liberti, G. L., Gardini, A., Orosei, R., D’Aversa, E., Filacchione, G., Coradini, A., 2005. Titan's ground reflectance retrieval from Cassini-IMS data taken during the July 2nd, 2004 Fly-By at 2 AM UT. Earth, Moon, and Planets 96, 109-117.

Alibert, Y., Mousis, O., 2007. Formation of Titan in Saturn's subnebula: Constraints from Huygens probe measurements. Astron. Astrophys. 465, 1051-1060.

Allen, M., Pinto, I. P., Yung, Y. L., 1980. Titan: Aerosol photochemistry and variations related to the sunspot cycle, Astrophys. J. 242, L125-L128.

Allison, M. A., 1992. Preliminary Assessment of the Titan planetary boundary layer. In: Proceedings of the Symposium on Titan, ESA Special Publication 338, 113-118.

Anders, E., Grevesse, N., 1989. Abundances of the elements: Meteoritic and solar. Geochim. Cosmochim. Acta 53, 197-214.

Anderson, C. M., Chanover, N. J., McKay, C. P., Rannou, P., Glenar, D. A., Hillman, J. J., 2004. Titan's haze structure in 1999 from spatially-resolved narrowband imaging surrounding the $0.94 \mu \mathrm{m}$ methane window. Geophys. Res. Let. 31, CiteID L17S06.

Andrews, D. G., Holton, J. R., Leovy, C. B., 1987. Middle Atmosphere Dynamics. New York: Academic Press.

Anicich, Vincent G., Milligan, Daniel B., Fairley, David A., McEwan, Murray J., 2000. Termolecular ion-molecule reactions in Titan's atmosphere, I Principal Ions with Principal Neutrals. Icarus 146, 118-124.

Anicich, Vincent G., McEwan, Murray J., 2002. Termolecular ion-molecule reactions in Titan's atmosphere. III. Clustering of Ions. Icarus 154, 522-530.

Artemieva, N., Lunine, J., 2003. Cratering on Titan: Impact melt, ejecta, and the fate of surface organics. Icarus 164, 471-480.

Artemieva, N., Lunine, J. I., 2005. Impact cratering on Titan II. Global melt, escaping ejecta, and aqueous alteration of surface organics. Icarus 175, 522-533.

Atkins, P. W., 1983. Molecular Quantum Mechanics. Oxford University Press.

Atreya, S. K., Donahue, T. M., Kuhn, W. R., 1978. Evolution of a nitrogen atmosphere on Titan, Science 201, 611-613.

Atreya, S. K., 1986 Atmospheres and Ionospheres of the Outer Planets and their Satellites. SpringerVerlag. New York.

Atreya, S. K., Adams, E. Y., Niemann, H. B., Demick-Montelara, J. E., Owen, T. C., Fulchignoni, M., Ferri, F., Wilson, E. H., 2006. Titan's methane cycle. Plan. Space Sci. 54, 1177-1187. 
Awal, M., Lunine, J. I., 1994. Moist convective clouds in Titan's atmosphere. Geophys. Res. Lett 21, 2491-2494.

Backes, H., Neubauer, F. M., Dougherty, M. K., Achilleos, N., André, N., Arridge, C. S., Bertucci, C., Jones, G. H., Khurana, K. K., Russell, C. T., Wennmacher, A., 2005. Titan's magnetic field signature during the first Cassini encounter. Science 308, 992-995.

Bakes, E. L. O., Lebonnois, S., Bauschlicher, Charles W., McKay, Christopher P., 2003. The role of submicrometer aerosols and macromolecules in $\mathrm{H}_{2}$ formation in the Titan haze. Icarus 161, 468-473.

Balsinger, H., Altwegg, K., Geiss, J., 1995. D/H and ${ }^{18} \mathrm{O} /{ }^{16} \mathrm{O}$ ratio in the hydronium ions and neutral water from in situ measurements in comet Halley. J. Geophys. Res. 100, 5827-5834.

Banaszkiewicz, M., Lara, L. M., Rodrigo, R., López-Moreno, J. J., Molina-Cuberos, G. J., 2000. A coupled model of Titan's atmosphere and ionosphere. Icarus 147, 386-404.

Banwell, C. N., 1986. Fundamentals of Molecular Spectroscopy. McGraw-Hill.

Baines, K. H., Brown, R. H., Matson, D. L., Nelson, R. M., Buratti, B. J., Bibring, J. P., Langevin, Y., Sotin, C., Carusi, A., Coradini, A., Clark, R. N., Combes, M., Drossart, P., Sicardy, B., Cruikshank, D. P., Formisano, V., Jaumann, R., 1992. VIMS/Cassini at Titan: Scientific objectives and observational scenarios. In: Proceedings of the Symposium on Titan, ESA Special Publication 338, 137-148.

Baines, K. H., Drossart, P., Momary, T. W., Formisano, V., Griffith, C., Bellucci, G., Bibring, J. P., Brown, R. H., Buratti, B. J., Capaccioni, F., Cerroni, P., Clark, R. N., Coradini, A., Combes, M., Cruikshank, D. P., Jaumann, R., Langevin, Y., Matson, D. L., McCord, T. B., Mennella, V., Nelson, R. M., Nicholson, P. D., Sicardy, B., Sotin, C., 2005. The atmospheres of Saturn and Titan in the near-infrared first results of Cassini/VIMS. Earth, Moon, and Planets 96, 119-147.

Baines, K. H., Drossart, P., Lopez-Valverde, M. A., Atreya, S. K., Sotin, C., Momary, Th. W., Brown, R. H., Buratti, B. J., Clark, R. N., Nicholson, Ph. D., 2006. On the discovery of CO nighttime emissions on Titan by Cassini/VIMS: Derived stratospheric abundances and geological implications. Plan. Space Sci. 54, 1552-1562.

Bakes, E. L. O., McKay, Christopher, P., Bauschlicher, Charles, W., 2002. Photoelectric charging of submicron aerosols and macromolecules in the Titan Haze. Icarus 157, 464-475.

Balucani, N., Asvany, O., Osamura, Y., Huang, L. C. L., Lee, Y. T., Kaiser, R. I., 2000. Laboratory investigation on the formation of unsaturated nitriles in Titan's atmosphere. Plan. Space Sci. 48, 447-462.

Barnes, J. W., Brown, R. H., Turtle, E. P., McEwen, A. S., Lorenz, R. D., Janssen, M., Schaller, E. L., Brown, M. E., Buratti, B. J., Sotin, C., Griffith, C., Clark, R., Perry, J., Fussner, S., Barbara, J., West, R., Elachi, C., Bouchez, A. H., Roe, H. G., Baines, K. H., Bellucci, G., Bibring, J.-P., Capaccioni, F., Cerroni, P., Combes, M., Coradini, A., Cruikshank, D. P., Drossart, P., Formisano, V., Jaumann, R., Langevin, Y., Matson, D. L., McCord, T. B., Nicholson, Ph. D., Sicardy, B., 2005. A 5-micron-bright spot on Titan: Evidence for surface diversity. Science 310, 92-95.

Barnes, Jason W., Brown, Robert H., Radebaugh, Jani, Buratti, Bonnie J., Sotin, Christophe, Le Mouelic, Stephane, Rodriguez, Sebastien, Turtle, Elizabeth P., Perry, Jason, Clark, Roger, Baines, Kevin H., Nicholson, Phillip D., 2006. Cassini observations of flow-like features in western Tui Regio, Titan. Geophys. Res. Let. 33, CiteID L16204.

Barnes, Jason W., Brown, Robert H., Soderblom, Laurence, Buratti, Bonnie J., Sotin, Christophe, Rodriguez, Sebastien, Le Mouèlic, Stephane, Baines, Kevin H., Clark, Roger, Nicholson, Phil, 2007. Global-scale surface spectral variations on Titan seen from Cassini/VIMS. Icarus 186, 242-258.

Bar-Nun, A., Kleinfeld, I., Ganor, E., 1988. Shape and optical properties of aerosols formed by photolysis of acetylene, ethylene and hydrogen cyanide J. Geophys. Res. 93, 8383-8387.

Barth, Erika L., Toon, Owen B., 2003. Microphysical modeling of ethane ice clouds in Titan's atmosphere. Icarus 162, 94-113. 
Barth, Erika L., Toon, Owen B., 2004. Properties of methane clouds on Titan: Results from microphysical modelling. Geophys. Res. Let. 31, CiteID L17S07.

Barth, Erika L., Toon, Owen B., 2006. Methane, ethane, and mixed clouds in Titan's atmosphere: Properties derived from microphysical modeling. Icarus 182, 230-250.

Barth, E. L., Rafkin, S. C. R., 2007. TRAMS: A new dynamic cloud model for Titan's methane clouds. Geophys. Res. Let. 34, CiteID L03203.

Beisker, W., Bittner, C., Bode, H. J., Buechner, R., Denzau, H., Dunham, D., Nezel, M., Reidel, E., 1989. The occultation of 28-Sgr by Titan - First results. Occultation News 4(13), 324-326.

Bénilan, Y., Jolly, A., Raulin, F., Guillemin, J.-C., 2006. IR band intensities of $\mathrm{DC}_{3} \mathrm{~N}$ and $\mathrm{HC}_{3}^{15} \mathrm{~N}$ : Implication for observations of Titan's atmosphere. Plan. Space Sci. 54, 635-640.

Bernard, J.-M., Coll, P., Coustenis, A., Raulin, F., 2003. Experimental simulation of Titan's atmosphere: Detection of ammonia and ethylene oxide. Plan. Space Sci. 51, 1003-1011.

Bernard, J.-M., Quirico, E., Brissaud, O., Montagnac, G., Reynard, B., McMillan, P., Coll, P., Nguyen, M.-J., Raulin, F., Schmitt, B., 2006. Reflectance spectra and chemical structure of Titan's tholins: Application to the analysis of Cassini Huygens observations. Icarus 185, 301-307.

Bézard, B., Coustenis, A., McKay, C. P., 1995. Titan's stratospheric temperature asymmetry: A radiative origin? Icarus 113, 267-276.

Bézard, B., Marten, A., Paubert, G., 1993. Detection of acetonitrile on Titan. Bull. Am. Astron. Soc. 25, 3, 1100 .

Bird, M. K., Allison, M., Asmar, S. W., Atkinson, D. H., Avruch, I. M., Dutta-Roy, R., Dzierma, Y., Edenhofer, P., Folkner, W. M., Gurvits, L. I., Johnston, D. V., Plettemeier, D., Pogrebenko, S. V., Preston, R. A., Tyler, G. L., 2005. The vertical profile of winds on Titan. Nature 438, 800-802.

Borucki, W. J., Giver, L. P., Mckay, C. P., Scattergood, T., Parris, J. E., 1988. Lightning production of hydrocarbons and HCN on Titan: Laboratory measurements. Icarus 76, 125-134.

Borucki, W. J., McKay, C. P., Whitten, R. C., 1984. Possible production by lightning of aerosols and trace gases in Titan's atmosphere. Icarus 60, 260-273.

Borucki, W. J., Whitten, R. C., Bakes, E. L. O., Barth, E., Tripathi, S., 2006. Predictions of the electrical conductivity and charging of the aerosols in Titan's atmosphere. Icarus 181, 527-544.

Borysow, A., Frommhold, L., 1986. Theoretical collision-induced roto-translational absorption spectra for modelling Titan's atmosphere: $\mathrm{H}_{2}-\mathrm{N}_{2}$ pairs. Astron. Astrophys. J. 303, 495-510.

Bouchez, A. H., Brown, M. E., 2005. Statistics of Titan's south polar tropospheric clouds. Astrophys. J. 618, L53-L56.

Brasseur, G., Solomon, S., 1986. Aeronomy of the Middle Atmosphere. Dortrecht: D. Reidel.

Brecht, Stephen H., Luhmann, Janet G., Larson, David J., 2000. Simulation of the Saturnian magnetospheric interaction with Titan. J. Geophys. Res. 105, 13119-13130.

Broadfoot, A. L., Belton, M. J. S., Takacs, P. Z., Sandel, B. R., Shemansky, D. E., Holberg, J. B., Ajello, J. M., Atreya, S. K., Donahue, T. M., Moos, H. W., Bertaux, J. L., Blamont, J. E., Strobel, D. F., McConnell, J. C., Dalgarno, A., Goody, R., McElroy, M. B., 1981. Extreme ultraviolet observations from Voyager 1 encounter with Saturn. Science 212, 206-211.

Brown, Michael E., Bouchez, Antonin H., Griffith, Caitlin A., 2002. Direct detection of variable tropospheric clouds near Titan's south pole. Nature 420, 795-797.

Bruston, P., Poncet, H., Raulin, F., Cossart-Marcos, C., Courtin, R., 1989. UV spectroscopy of Titan's atmosphere, planetary organic chemistry, and prebiological synthesis, I, Absorption spectra of gaseous propynenitrile $\mathrm{ad}^{2}$-butynenitrile in the 185 - to 250 -nm region. Icarus 78, 38-54.

Burr, D. M., Emery, J. P., Lorenz, R. D., Collins, G. C., Carling, P. A., 2006. Sediment transport by liquid surficial flow: Application to Titan. Icarus 181, 235-242.

Cabane, M., Chassefière, E., 1993. Growth of aerosols in Titan's atmosphere and related time scales: A stochastic approach. Geophys. Res. Let. 20, 967-970.

Cabane, M., Chassefière, E., 1995. Laboratory simulations of Titan's atmosphere: Organic gases and aerosols. Plan. Space Sci. 43, 47-65. 
Cabane, M., Chassefière, E., Israel, G., 1992. Formation and growth of photochemical aerosols in Titan's atmosphere. Icarus 96, 176-189.

Cabane, M., Chassefière, E., Botet, R., McKay, C. P., Courtin, R., 1995. Titan's geometric albedo: Role of the fractal structure of the aerosols. Icarus 118, 355-372.

Cabane, M., Rannou, P., Chassefière, E., Israel, G., 1993. Fractal aggregates in Titan's atmosphere. Plan. Space Sci. 41, 257-267.

Calcutt, S. B., Taylor, F. W., Ade, P., Kunde, V. G., Jennings, D., 1992. The composite infrared spectrometer. J. Brit. Interplanetary Soc. 45, 811-816.

Caldwell, J., Cunningham, C. C., Anthony, D., White, H. P., Groth, E. J., Hasan, H., Noll, K., Smith, P. H., Tomasko, M. G., Weaver, H. A., 1992. Titan: Evidence for seasonal change - A comparison of Hubble Space Telescope and Voyager images. Icarus 97, 1-9.

Caldwell, J., Owen, T., Rivolo, A. R., Moore, V., Hunt, G. E., Butterworth, P. S., 1981. Observations of Uranus, Neptune and Titan by the International Ultraviolet Explorer. Astron. Astrophys. J. 86, 298-305.

Campbell, Donald B., Black, Gregory J., Carter, Lynn M., Ostro, Steven J., 2003. Radar evidence for liquid surfaces on Titan. Science 302, 431-434.

Campbell, B. A., 2007. A rough-surface scattering function for Titan radar studies. Geophys. Res. Let. 34, CiteID L14203.

Canosa, A., Páramo, A., Le Picard, S. D., Sims, I. R., 2007. An experimental study of the reaction kinetics of $\mathrm{C}_{2}\left(\mathrm{X}^{1} \Sigma_{g}^{+}\right)$with hydrocarbons $\left(\mathrm{CH}_{4}, \mathrm{C}_{2} \mathrm{H}_{2}, \mathrm{C}_{2} \mathrm{H}_{4}, \mathrm{C}_{2} \mathrm{H}_{6}\right.$ and $\left.\mathrm{C}_{3} \mathrm{H}_{8}\right)$ over the temperature range $24-300 \mathrm{~K}$ : Implications for the atmospheres of Titan and the Giant Planets. Icarus 187, 558-568.

Capone, L. A., Dubach, J., Prasad, S. S., Whitten, R. C., 1983. Galactic cosmic rays and $\mathrm{N}_{2}$ dissociation on Titan. Icarus 55, 73-82.

Carrasco, N., Dutuit, O., Thissen, R., Banaszkiewicz, M., Pernot, P., 2007. Uncertainty analysis of bimolecular reactions in Titan ionosphere chemistry model. Plan. Space Sci. 55, 141-157.

Carlson, R., Smythe, W., Bained, K., Barbinis, E., Becker, K., Burns, R., Calcutt, S., Calvin, W., Clark, R., Danielson, G., Davies, A., Drossart, P., Encrenaz, Th., Fanale, F., Granahan, J., Hansen, G., Herrera, P., Hibbitts, C., Hui, J., Irwin, P., Johnson, T., Kamp, L., Kieffer, H., Leader, F., Lellouch, E., Lopes-Gautier, R., Matson, D., McCord, T., Mehlman, R., Ocampo, A., Orton, G., Roos-Serote, M., Segura, M., Shirley, J., Soderblom, L., Stevenson, A., Torson, J., Taylor, F., Weir, A., Weissman, P., 1996. Near-infrared spectroscopy and spectral mapping of Jupiter and the Galilean Satellites: First results from Galileo's initial orbit. Science 274, 385-388.

Cassini, J. D., 1671. Observations concerning Saturn. Phil. Trans. 6, 3024-3027.

Cassini, J. D., 1673a. Découverte de deux Nouvelles Planètes autour de Saturne, Paris.

Cassini, J. D., 1673b. Discovery of two new planets about Saturn, made in the Royal Parisian Observatory by Signor Cassini. Phil. Trans. 8, 5178-5185.

Cassini, J. D., 1676. An extract of Signor Cassini's letter concerning a spot lately seen in the Sun: Together with a remarkable observation of Saturn by the same. Phil. Trans. 11, 689-690.

Cassini, J. D., 1686. An extract of the Journal des Scavans. of April 22nd 1686. Giving an account of two new satellites of Saturn, discovered lately by Mr. Cassini at the Royal Observatory at Paris. Phil. Trans. 16, 79-85.

Celnikier, L. M., 1993. Basics of Space Flight. Editions Frontières.

Cerceau, F., Raulin, F., Courtin, R., Gautier, D., 1985. Infrared spectra of gaseous mononitriles: Application to the atmosphere of Titan. Icarus 62, 207-220, 1985.

Cess, R. D., Owen, T., 1973. Titan: The effect of noble gases on an atmospheric greenhouse. Nature 244, 272-273.

Chamberlain, J. W., Hunten, D. M., 1987. Theory of Planetary Atmospheres. Academic Press, San Diego, Calif.

Chanover, N. J., Anderson, C. M., McKay, C. P., Rannou, P., Glenar, D. A., Hillman, J. J., Blass, W. E., 2003. Probing Titan's lower atmosphere with acousto-optic tuning. Icarus 163, 150-163. 
Chassefière, E, Cabane, M., 1995. Two formation regions for Titan's Hazes: Indirect clues and hypothesised chemical synthesis processes. Plan. Space Sci. 43, 91-103.

Chiu, Wang-Ting, Hsu, Hui-Chun, Kopp, Andreas, Ip, Wing-Huen, 2001. On ion outflows from Titan's exosphere. Geophys. Res. Let. 28, 3405-3408.

Clark, R. N., Fanale, F. P., Gaffey, M. J., 1986. Surface composition of natural satellites. In: Satellites (Burns, J. A. and Matthews, M. S., eds.), The Univ. of Arizona Press, Tucson, 437-491.

Clark, R. N., Brown, R. H., Owensby, P. D., Steele, A., 1984. Saturn's satellites: Near-infrared spectrophotometry $(0.65-2.5 \mu \mathrm{m})$ of the leading and trailing sides and compositional implications. Icarus 58, 265-281, 1984.

Clarke, D. W., Ferris, J. P., 1995. Photodissociation of cyanoacetylene: Application to the atmospheric chemistry of Titan. Icarus 115, 119-126.

Clarke, David W., Joseph, Jeffrey C., Ferris, James P., 2000. The design and use of a photochemical flow reactor: A laboratory study of the atmospheric chemistry of cyanoacetylene on Titan. Icarus 147, 282-291.

Clausen, K., Sainct, H., 1994. The Huygens probe and mission design. Adv. Space Res. 14(12), 189-195.

Coll, P., Coscia, D., Gazeau, M. C., de Vanssay, E., Guillemin, J. C., Raulin, F., 1995. Organic chemistry in Titan's atmosphere: New data from laboratory simulations at low temperature. Adv. Space Res. 16(2), 93-103.

Coll, P., Coscia, D., Gazeau, M. C., Guez, L., Raulin, F., 1998. Review and latest results of laboratory investigation of Titan's aerosol. Origins of Life 28, 195-213.

Coll, P., Coscia, D., Smith, N., Gazeau, M.-C., Ramírez, S. I., Cernogora, G., Israël, G., Raulin, F., 1999. Experimental laboratory simulation of Titan's atmosphere: Aerosols and gas phase. Plan. Space Sci. 47, 1331-1340.

Coll, P., Guillemin, J.-C., Gazeau, M.-C., Raulin, F., 1999. Report and implications of the first observation of C4N2 in laboratory simulations of Titan's atmosphere. Plan. Space Sci. 47, $1433-1440$.

Coll, P., Bernard, J.-M., Navarro-González, R., Raulin, F., 2003. Oxirane: An exotic oxygenated organic compound on Titan? The Astrophys. J. 598, 700-703.

Collins, G. C., 2005. Relative rates of fluvial bedrock incision on Titan and Earth. Geophys. Res. Let. 32, CiteID L22202.

Comas Solá, J., 1908. Observationes des Satellites Principaux de Jupiter et de Titan. Astron. Nachr. 179, 289-290.

Combes, M., Vapillon, L., Gendron, E., Coustenis, A., Lai, O., Wittemberg, R., Sirdey, R., 1997. Spatially resolved images of Titan by means of adaptive optics. Icarus 129, 482-497.

Consolmagno, G. J., Lewis, J. S., 1978. The evolution of icy satellites interiors and surfaces. Icarus 34, 280-293.

Courtin, R., 1988. Pressure-induced absorption coefficients for radiative transfer calculations in Titan's atmosphere. Icarus 75, 245-254.

Courtin, R., Gautier, D., McKay, C. P., 1995. Titan's thermal emission spectrum: Re-analysis of the Voyager infrared measurements. Icarus 114, 144-163.

Courtin, R., Wagener, R., McKay, C. P., Caldwell, J., Fricke,K.-H., Raulin, F., Bruston, P., 1991. UV spectroscopy of Titan's atmosphere, planetary organic chemistry and prebiological synthesis. II. Interpretation of new IUE observations in the 220-335 nm range. Icarus 90, 43-56.

Courtin, R., Gautier, D., McKay, C. P., 1996. Titan's thermal emission spectrum: Reanalysis of the Voyager infrared measurements. Icarus 114, 144-162.

Courtin, R., Kim, S. J., 2002. Mapping of Titan's tropopause and surface temperatures from Voyager IRIS spectra. Plan. Space Sci. 50, 309-321.

Courtin, R., 2005. Aerosols on the giant planets and Titan. Space Science Reviews 116, 185-199.

Coustenis, A., 1990. Spatial variations of temperature and composition in Titan's atmosphere: Recent results. Ann. Geophysicae 8, 645-652. 
Coustenis, A., 1991 Titan's atmosphere: Recent developments. Vistas in Astronomy 34, 11-50.

Coustenis, A., 1995. Titan's atmosphere and surface: Parallels and differences with the primitive Earth.

In: "Comparative planetology with an Earth prospective", Earth, Moon, and Planets 67, Chahine,

M. T., A'Hearn, M. F. and Rahe, J. eds., 95-100.

Coustenis, A., 1998. Titan in the Solar System. Planet. Space Sci. 46, 1085-1097.

Coustenis, A., 2005. Formation and evolution of Titan's atmosphere. Space Sci. Rev. 116, 171-184.

Coustenis, A., 2007. What Cassini-Huygens has revealed about Titan. Astronomy and Geophysics 48, 2.14-2.20.

Coustenis, A., Bézard, B., Gautier, D., 1989a. Titan's atmosphere from Voyager infrared observations:

I. The gas composition of Titan's equatorial region. Icarus 80, 54-76.

Coustenis, A., Bézard, B., Gautier, D., 1989b. Titan's atmosphere from Voyager infrared observations:

II. The $\mathrm{CH}_{3} \mathrm{D}$ abundance and $\mathrm{D} / \mathrm{H}$ ratio from the $900-1200 \mathrm{~cm}^{-1}$ spectral region. Icarus 82 , 67-80.

Coustenis, A., Bézard, B., Gautier, D., Marten, A., Samuelson, R. E., 1991. Titan's atmosphere from Voyager infrared observations. III. Vertical distributions of hydrocarbons and nitriles near Titan's north pole. Icarus 89, 152-167.

Coustenis, A., Encrenaz, Th., Bézard, B., Bjoraker, G., Graner, G., Dang-Nhu, M., Arie, E., 1993. Modelling Titan's thermal infrared spectrum for high-resolution space observations. Icarus 102, 240-260.

Coustenis, A., Bézard, B., 1995a. Titan's atmosphere from Voyager infrared observations. IV. Latitudinal variations of temperature and composition. Icarus 115, 126-140.

Coustenis, A., Lellouch, E., Maillard, J.-P., McKay, C. P., 1995b. Titan's surface: Composition and variability from the near-infrared albedo. Icarus 118, 87-104.

Coustenis, A., Schneider, J., Bockelée-Morvan, D., Rauer, H., Wittenberg, R., Chassefière, E., Greene, T., Penny, A., Guillot, T., 1997. Spectroscopy of 51 Peg B: Search for atmospheric signatures. In: Planets beyond the Solar System and the Next Generation of Space Missions. ASP Conference Series, 119, 101-105.

Coustenis, A., Salama, A., Lellouch, L., Encrenaz, Th., Bjoraker, G., Samuelson, R., de Graauw, Th., Feuchtgruber, H., Kessler, M. F., 1998. Evidence for water vapor in Titan's atmosphere from ISO/SWS data. Astron. Astrophys. 336, L85-L89.

Coustenis, A., Schmitt, B., Khanna, R., Trotta, F., 1999. Plausible condensates in Titan's stratosphere from Voyager IR spectra. Plan. Space Sci. 47, 1305-1329.

Coustenis, A., Gendron, E., Lai, O., Véran., J.-P. Woillez, J., Combes, M., Vapillon, L., Fusco, Th., Mugnier, L., Rannou, P., 2001. Images of Titan at 1.3 and 1.6 microns with adaptive optics at the CFHT. Icarus 154, 501-515.

Coustenis, A., Salama, A., Schulz, B., Ott, S., Lellouch, E., Encrenaz, Th., Gautier, D., Feuchtgruber, H. 2003. Titan's atmosphere from ISO mid-infrared spectroscopy. Icarus 161, 383-403.

Coustenis, A., 2005. Formation and evolution of Titan's atmosphere. Space Sci. Rev., 116, 171-184.

Coustenis, A., Hirtzig, M., Gendron, E., Drossart, P., Lai, O., Combes, M., Negrao, A., 2005. Maps of Titan's surface from 1 to 2.5 micron. Icarus 177, 89-105.

Coustenis, A., Negrao, A., Salama, A., Schulz, B., Lellouch, E., Rannou, P., Drossart, P., Encrenaz, Th., Schmitt, B., Boudon, V., Nikitin, A., 2006. Titan's 3-micron spectral region from ISO highresolution spectroscopy. Icarus 180, 176-185.

Coustenis, A., Achterberg, R., Conrath, B., Jennings, D., Marten, A., Gautier, D., Bjoraker, G., Nixon, C., Romani, P., Carlson, R., Flasar, M., Samuelson, R. E., Teanby, N., Irwin, P., Bézard, B., Orton, G., Kunde, V., Abbas, M., Courtin, R., Fouchet, Th., Hubert, A., Lellouch, E., Mondellini, J., Taylor, F. W., Vinatier, S., 2007. The composition of Titan's stratosphere from Cassini/CIRS mid-infrared spectra. Icarus 189, 35-62.

Coustenis, A., Jennings, D., Jolly, A., Bénilan, Y., Nixon, C., Gautier, D., Vinatier, S., Bjoraker, G., Romani, P., 2008a. Detection of $\mathrm{C}_{2} \mathrm{HD}$ and the $\mathrm{D} / \mathrm{H}$ ratio on Titan. Icarus, in press. 
Coustenis, A., Atreya, S., Balint, T., Brown, R. H., Dougherty, M., Ferri, F., Fulchignoni, M., Gautier, D., Gowen, R., Griffith, C., Gurvits, L., Jaumann, R., Langevin, Y., Leese, M., Lunine, J., McKay, C. P., Moussas, X., Müller-Wodarg, I., Neubauer, F., Owen, T., Raulin, F., Sittler, E., Sohl, F., Sotin, C., Tobie, G., Tokano, T., Turtle, E, Wahlund, J.-E., Waite, H., Baines, K., Balmont. J., Dandouras, I., Krimigis, T., Lellouch, E., Lorenz, R., Morse, A., Porco, C., Hirtizig, M., Saur, J., Coates, A., Spilker, T., Zarnecki, J. and 113 co-authors, 2008b. TandEM: Titan and Enceladus mission. Astrophysical Instruments and Methods, in press.

Cravens, T. E., Robertson, I. P., Clark, J., Wahlund, J.-E., Waite, J. H., Ledvina, S. A., Niemann, H. B., Yelle, R. V., Kasprzak, W. T., Luhmann, J. G., McNutt, R. L., Ip, W.-H., De La Haye, V., Müller-Wodarg, I., Young, D. T., Coates, A. J., 2005. Titan's ionosphere: Model comparisons with Cassini Ta data. Geophys. Res. Let. 32, CiteID L12108.

Cravens, T. E., Robertson, I. P., Waite, J. H., Yelle, R. V., Kasprzak, W. T., Keller, C. N., Ledvina, S. A., Niemann, H. B., Luhmann, J. G., McNutt, R. L., Ip, W.-H., De La Haye, V., Mueller-Wodarg, I., Wahlund, J.-E., Anicich, V. G., Vuitton, V., 2006. Composition of Titan's ionosphere. Geophys. Res. Let. 33, CiteID L07105.

Crespin, A., Lebonnois, S., Vinatier, S., Bézard, B., Coustenis, A., Teanby, N. A., Achterberg, R. K., Rannou, P., 2008. Diagnostics of Titan's stratospheric dynamics using CIRS/Cassini data and the IPSL General Circulation Model. Icarus, in press.

Cruikshank, D. P., Morgan, J. S., 1980. Titan: Suspected near infrared variability. Astrophys. J. 235, L53-L54.

Dandouras, J., Amsif, A., 1999. Production and imaging of energetic neutral atoms from Titan's exosphere: A 3-D model. Plan. Space Sci. 47, 1355-1369.

Danehy, R. G., Owen, T., Lutz, B. L., Woodman, J. H., 1978. Detection of the Kuiper Bands in the Spectrum of Titan. Icarus 35, 247-251.

Danielson, R. E., Caldwell, J. J., Larach, D. R., 1973. An inversion in the atmosphere of Titan. Icarus 20, 437-443, 1973.

De Bergh, C., Lutz, B. L., Owen, T., Chauville, J., 1988. Monodeuterated methane in the outer solar system. III. Its abundance on Titan. Astron. Astrophys. J. 329, 951-955.

De Kok, R., Irwin, P. G. J., Teanby, N. A., Lellouch, E., Bézard, B., Vinatier, S., Nixon, C. A., Fletcher, L., Howett, C., Calcutt, S. B., Bowles, N. E., Flasar, F. M., Taylor, F. W., 2007. Oxygen compounds in Titan's stratosphere as observed by Cassini CIRS. Icarus 186, 354-363.

De La Haye, V., Waite, J. H., Johnson, R. E., Yelle, R. V., Cravens, T. E., Luhmann, J. G., Kasprzak, W. T., Gell, D. A., Magee, B., Leblanc, F., Michael, M., Jurac, S., Robertson, I. P., 2007. Cassini ion and neutral mass spectrometer data in Titan's upper atmosphere and exosphere: Observation of a suprathermal corona. J. Geophys. Res. 112, CiteID A07309.

De Pater, I., Ádámkovics, M., Bouchez, A. H., Brown, M. E., Gibbard, S. G., Marchis, F., Roe, H. G., Schaller, E. L., Young, E., 2006. Titan imagery with Keck adaptive optics during and after probe entry. J. Geophys. Res. 111, CiteID E07S05.

Delitsky, M. L., Thompson, W. R., 1987. Chemical processes in Triton's atmosphere and surface. Icarus 70, 354-365.

Desch, M. D., Kaiser, M. L., 1990. Upper limit set for level of lightning activity on Titan. Nature 343, 442-444.

Dimitrov, Vasili I., Bar-Nun, Akiva, 1999. Admissible height of local roughness of Titan's landscape. J. Geophys. Res. 104, 5933-5938.

Dimitrov, Vasili, Bar-Nun, Akiva, 2002. Aging of Titan's aerosols. Icarus 156, 530-538.

Dimitrov, Vasili, Bar-Nun, Akiva, 2003. Hardening of Titan's aerosols by their charging. Icarus 166 , $440-443$.

Dire, J. R., 2000. Seasonal photochemical and meridional transport model for the stratosphere of Titan. Icarus. 145, 428-444.

Dóbé, Zoltán, Szegõ, Károly, 2005. Wave activity above the ionosphere of Titan: Predictions for the Cassini mission. J. Geophys. Res. 110, CiteID A03224. 
Dóbé, Z., Szego, K., Quest, K. B., Shapiro, V. D., Hartle, R. E., Sittler, E. C., 2007. Nonlinear evolution of modified two-stream instability above ionosphere of Titan: Comparison with the data of the Cassini Plasma Spectrometer. J. Geophys. Res. 112, CiteID A03203.

Dollfus, A., 1961. Visual and Photographic Studies of Planets at the Pic Du Midi. In: The Solar System and Planets III. Planets and Satellites. (Kuiper, Middlehurst, eds.), 534-571. University of Chicago Press.

Dubouloz, N., Raulin, F., Lellouch, E., Gautier, D., 1989. Titan's hypothesized ocean properties: The influence of surface temperature and atmospheric composition uncertainties, Icarus 82, 81-94.

Eberhardt, P., Reber, M., Krankowsky, D., Hidges, R., 1995. The D/H and ${ }^{18} \mathrm{O} /{ }^{16} \mathrm{O}$ ratios in water from comet P/Halley. Astron. Astrophys. 302, 301-316.

Ehrenfreund, P., Boon, J. J., Commandeur, J., Sagan, C., Thompson, W. R., Khare, B. N., 1995. Analytical pyrolysis experiments of Titan aerosol analogues in preparation for the CassiniHuygens Mission. Adv. Space Res. 15(3), 335-342.

Elachi, C., Wall, S., Allison, M., Anderson, Y., Boehmer, R., Callahan, P., Encrenaz, P., Flamini, E., Franceschetti, G., Gim, Y., Hamilton, G., Hensley, S., Janssen, M., Johnson, W., Kelleher, K., Kirk, R., Lopes, R., Lorenz, R., Lunine, J., Muhleman, D., Ostro, S., Paganelli, F., Picardi, G., Posa, F., Roth, L., Seu, R., Shaffer, S., Soderblom, L., Stiles, B., Stofan, E., Vetrella, S., West, R., Wood, C., Wye, L., Zebker, H., 2005. Cassini radar views the surface of Titan. Science 308, 970-974.

Elachi, C., Wall, S., Janssen, M., Stofan, E., Lopes, R., Kirk, R., Lorenz, R., Lunine, J., Paganelli, F., Soderblom, L., Wood, C., Wye, L., Zebker, H., Anderson, Y., Ostro, S., Allison, M., Boehmer, R., Callahan, P., Encrenaz, P., Flamini, E., Francescetti, G., Gim, Y., Hamilton, G., Hensley, S., Johnson, W., Kelleher, K., Muhleman, D., Picardi, G., Posa, F., Roth, L., Seu, R., Shaffer, S., Stiles, B., Vetrella, S., West, R., 2006. Titan Radar Mapper observations from Cassini's T3 fly-by. Nature 441, 709-713.

Elachi, C., Wall, S., Janssen, M., Stofan, E., Lopes, R., Kirk, R., Lorenz, R., Lunine, J., Paganelli, F., Soderblom, L., Wood, C., Wye, L., Zebker, H., Anderson, Y., Ostro, S., Allison, M., Boehmer, R., Callahan, P., Encrenaz, P., Flamini, E., Francescetti, G., Gim, Y., Hamilton, G., Hensley, S., Johnson, W., Kelleher, K., Muhleman, D., Picardi, G., Posa, F., Roth, L., Seu, R., Shaffer, S., Stiles, B., Vetrella, S., West, R., 2006. Corrigendum: Titan Radar Mapper observations from Cassini's T3 fly-by. Nature 442, 322.

Encrenaz, Th., Gulkis, S., Lellouch., E., 1991. Heterodyne spectroscopy of planetary and satellite atmospheres in the millimeter and submillimeter range. In: Coherent detection techniques at millimeter wavelength and their applications. (Encrenaz, P., Kollberg, E., Gulkis, S., Winnewisser, G., eds.), Nova Science.

Encrenaz, Thérèse, 2003. ISO observations of the giant planets and Titan: What have we learnt? Plan. Space Sci. 51, 89-103.

Engel, S., Lunine, J. I., Hartmann, W. K., 1995. Cratering on Titan and implications for atmospheric history. Planet. Space Sci., 43(9), 1059-1066.

Engel, S., Lunine, J. I., Norton, D. L., 1994. Silicate interactions with ammonia-water fluids on early Titan. J. Geophys. Res. 99, E2, 3745-3752.

English, M. A., Lara, L. M., Lorenz, R. D., Ratcliff, P. R., Rodrigo, R., 1996. Ablation and chemistry of meteoric materials in the atmosphere of Titan. Adv. Space Res. 12, 157-160.

Eshleman, V. R., Lindal, G. F., Tyler, G. L., 1983. Is Titan Wet or Dry? Science 221, 53-55.

Farinella, P., Paolicchi, P., Strom, R. G., Kargel, J. S., Zappalà, V., 1990. The fate of Hyperion's fragments. Icarus 83, 186-204.

Farinella, P., Marzari, F., Matteoli, S., 1997. The disruption of Hyperion and the origin of Titan's atmosphere. Astron. J. 113, 2312-2316.

Fegley, Jnr. B., Prinn, R. G., 1989. Solar Nebula chemistry: Implications for volatiles in the solar system. In: The Formation and Evolution of Planetary Systems. (Weaver, Danley, eds.), 171-211. Cambridge University Press. 
Feuchtgruber, H., Lellouch, E., de Graauw, Th., Bézard, B., Encrenaz, T., Griffin, M., 1997. External supply of oxygen to the atmospheres of the giant planets. Nature 389, 159-162.

Fink, U., Larson, H. P., 1979. The infrared spectra of Uranus, Neptune, Titan from 0.8 to 2.5 microns. Astron. Astrophys. 233, 1021-1040.

Fink, U., Larson, H. P., 1978. Deuterated methane observed on Titan. Science 201, 343-345.

Fink, U, Larson, H. P., 1979. The infra-red spectra of Uranus, Neptune and Titan from 0.8 to 2.5 Microns. Astrophys. J. 233, 1021-1040.

Fischer, G., Tokano, T., Macher, W., Lammer, H., Rucker, H. O., 2004. Energy dissipation of possible Titan lightning strokes. Plan. Space Sci. 52, 447-458.

Flasar, F. M., Conrath, B. J., 1990. Titan's stratospheric temperatures: A case for dynamical inertia? Icarus 85, 346-354.

Flasar, F. M., Samuelson, R. E., Conrath, B. J., 1981. Titan's atmosphere: Temperature and dynamics. Nature 292, 693-698.

Flasar, F. M., 1983. Oceans on Titan? Science 221, 55-57.

Flasar, F. M., 1998. The composition of Titan's atmosphere: A meteorological perspective. Planet. Space Sci. 46, 1109-1124.

Flasar, F. M., 1998. The dynamic meteorology of Titan. Planet. Space Sci. 46, 1125-1148.

Flasar, F. M., Kunde, V. G., Achterberg, R. K., Conrath, B. J., Simon-Miller, A. A., Nixon, C. A., Gierasch, P. J., Romani, P. N., Bézard, B., Irwin, P., Bjoraker, G. L., Brasunas, J. C., Jennings, D. E., Pearl, J. C., Smith, M. D., Orton, G. S., Spilker, L. J., Carlson, R., Calcutt, S. B., Read, P. L., Taylor, F. W., Parrish, P., Barucci, A., Courtin, R., Coustenis, A., Gautier, D., Lellouch, E., Marten, A., Prangé, R., Biraud, Y., Fouchet, T., Ferrari, C., Owen, T. C., Abbas, M. M., Samuelson, R. E., Raulin, F., Ade, P., Césarsky, C. J., Grossman, K. U., Coradini, A., 2004. An intense stratospheric jet on Jupiter. Nature 427, 132-135.

Flasar, F. M., Achterberg, R. K., Conrath, B. J., Bjoraker, G. L., Jennings, D. E., Pearl, J. C., Romani, P. N., Simon-Miller, A. A., Kunde, V. G., Nixon, C. A., Bézard, B., Orton, G. S., Spilker, L. J., Irwin, P., Teanby, N. A., Spencer, J. A., Owen, T. C., Brasunas, J. C., Segura, M. E., Carlson, R., Matmoukine, A., Giearasch, P. J., Schinlder, P. J., Ferrari, C., Showalter, M. R., Barucci A., Courtin R., Coustenis A., Fouchet T., Gautier D., Lellouch E., Marten A., Prangé, R., Strobel, D. F., Calcutt S. B., Read P. L., Taylor F. W., Bowles, N., Samuelson R. E., Abbas M. M., Raulin F., Ade P., Edgington, S., Pilorz, S., Wallis, B., Wishnow, E. 2005. Temperatures, winds, and composition in the Saturnian system. Science 307, 1247-1251.

Flasar, F. M., Achterberg, R. K., Conrath, B. J., Gierasch, P. J., Kunde, V. G., Nixon, C. A., Bjoraker, G. L., Jennings, D. E., Romani, P. N., Simon-Miller, A. A., Bézard, B., Coustenis, A., Irwin, P. G. J., Teanby, N. A., Brasunas, J., Pearl, J. C., Segura, M. E., Carlson, R., Matmoukine, A., Schinder, P. J., Barucci, A., Courtin, R., Fouchet, T., Gautier, D., Lellouch, E., Marten, A., Prangé, R., Vinatier, S., Strobel, D. F., Calcutt S. B., Read, P. L., Taylor, F. W., Bowles, N., Samuelson, R. E., Orton, G. S., Spilker, L. J., Owen, T. C., Spencer, J. A., Showalter, M. R., Ferrari, C., Abbas, M. M., Raulin, F., Edgington, S., Ade P., Wishnow, E. H., 2005. Titan's atmospheric temperatures, winds, and composition. Science 308, 975-978.

Folkner, W. M., Asmar, S. W., Border, J. S., Franklin, G. W., Finley, S. G., Gorelik, J., Johnston, D. V., Kerzhanovich, V. V., Lowe, S. T., Preston, R. A., Bird, M. K., Dutta-Roy, R., Allison, M., Atkinson, D. H., Edenhofer, P., Plettemeier, D., Tyler, G. L., 2006. Winds on Titan from groundbased tracking of the Huygens probe. J. Geophys. Res. 111, CiteID E07S02.

Fortes, A. D., 2000. Exobiological implications of a possible Ammonia-Water ocean inside Titan. Icarus 146, 444-452.

Fortes, A. Dominic, Grindrod, Peter M., 2006. Modelling of possible mud volcanism on Titan. Icarus 182, 550-558.

Fortes, A. D., Grindrod, P. M., Trickett, S. K., Voèadlo, L., 2007. Ammonium sulfate on Titan: Possible origin and role in cryovolcanism. Icarus 188, 139-153. 
Fouchet, Th., Bézard, B., Encrenaz, Th., 2005. The planets and Titan observed by ISO. Space Science Reviews 119, 123-139.

Frère, C., Raulin, R., Israel, G., Cabane, M., 1990. Microphysical modelling of Titan's aerosols: Application to the in situ analysis. Adv. Space Res. 10, 159-163.

Fujii, Toshihiro, Arai, Norihisa, 1999. Analysis of N-containing hydrocarbon species produced by a CH_4/N_2 microwave discharge: Simulation of Titan's atmosphere. Astrophys. J. 519, 858-863.

Friedson, A. J. Yung., Y. L. 1984. The thermosphere of Titan. J. Quant. Spectrosc. Radiat. Transfer 89, 85-90.

Fulchignoni, M., Ferri, F., Angrilli, F., Ball, A. J., Bar-Nun, A., Barucci, M. A., Bettanini, C., Bianchini, G., Borucki, W., Colombatti, G., Coradini, M., Coustenis, A., Debei, S., Falkner, P., Fanti, G., Flamini, E., Gaborit,V., Grard, R., Hamelin, M., Harri, A. M., Hathi, B., Jernej, I., Leese, M. R., Lehto, A., Lion Stoppato, P. F., Lopez-Moreno, J. J., Mäkinen, T., McDonnell, J. A. M., McKay, C. P., Molina-Cuberos, G., Neubauer, F. M., Pirronello, V., Rodrigo, R., Saggin, B., Schwingenschuh, K., Seiff, A.,Simoes, F., Svedhem, H., Tokano, T., Towner, M. C., Trautner, R., Withers, P., Zarnecki, J. C., 2005. Titan's physical characteristics measured by the Huygens Atmospheric Instrument (HASI). Nature 438, 785-791.

Galand, Marina, Lilensten, Jean, Toublanc, Dominique, Maurice, Sylvestre, 1999. The ionosphere of Titan: Ideal diurnal and nocturnal cases. Icarus 140, 92-105.

Galand, M., Yelle, R. V., Coates, A. J., Backes, H., Wahlund, J.-E., 2006. Electron temperature of Titan's sunlit ionosphere. Geophys. Res. Let. 33, CiteID L21101.

Garnier, P., Dandouras, I., Toublanc, D., Brandt, P. C., Roelof, E. C., Mitchell, D. G., Krimigis, S. M., Krupp, N., Hamilton, D. C., Waite, H., 2007. The exosphere of Titan and its interaction with the kronian magnetosphere: MIMI observations and modelling. Plan. Space Sci. 55, 165-173.

Gautier, D., 1995. Titan's atmosphere composition: certainties and speculations. Adv. Space Res. 15(3), 295-301.

Gautier, D., 1997. The aeronomy of Titan. In: Huygens: Science payload and mission (Lebreton, J.-P., ed.), ESA Special report SP-1177, 359-364.

Gautier, D., Owen, T., 1985. Observational constraints on models for giant planet formation. In: Protostars and Planets II (Black, D. C., Matthews, M. S., eds.), 832-846. Univ. of Arizona Press, Tucson.

Gautier, D., Owen, T., 1988. The composition of outer planet atmospheres. In: Origin and evolution of planetary and satellite atmospheres (Atreya, S. Pollack, J. Matthews, M. S., eds.), 487-512 Univ. of Arizona Press, Tucson.

Gautier, D., Owen, T., 1989. Titan: Some new results. Adv. Space Res. 9, 73-78.

Gautier, D., Raulin, F. 1997, 'Chemical composition of Titan's atmosphere', in Wilson, A. (ed.), Huygens: Science, Payload and Mission, ESA Special report SP-1177, 359-364.

Gautier, D., Hersant, F., 2005. Formation and composition of planetesimals: Trapping volatiles by clathration. Space Sci. Rev. 116, 25-52.

Gazeau, M.-C., Cottin, H., Vuitton, V., Smith, N., Raulin, F., 2000. Experimental and theoretical photochemistry: Application to the cometary environment and Titan's atmosphere. Plan. Space Sci. 48, 437-445.

Ge, Su-Hong, Cheng, Xin-Lu, Yang, Xiang-Dong, Liu, Zi-Jiang, Wang, Wei, 2006. Calculations of the thermochemistry of six reactions leading to ammonia formation in Titan's atmosphere. Icarus 183, 153-158.

Geballe, T. R., Kim, S. J., Noll, K. S., Griffith, C. A., 2003. High-resolution 3 micron spectroscopy of molecules in the mesosphere and troposphere of Titan. Astrophys. J. 583, L39-L42.

Geiss, J., Gloecker, G. 1998, 'Abundances of deuterium and helium-3 in the proto-solar cloud. Space Sci. Rev. 82, 239-250.

Gendron, E., Coustenis, A., Drossart, P., Combes, M., Hirtzig, M., Lacombe, F., Rouan, D., Collin, C., Pau, S., Lagrange, A.-M., Mouillet, D., Rabou, P., Fusco, Th., Zins, S., 2004. VLT/NACO adaptive optics imaging of Titan. Astron. Astroph. 417, L21-L24. 
Ghafoor, Nadeem A.-L., Zarnecki, John C., Challenor, Peter, Srokosz, Meric A., 2000. Wind-driven surface waves on Titan. J. Geophys. Res. 105, 12077-12092.

Gibbard, S. G., Macintosh, B., Gavel, D., Max, C. E., de Pater, I., Ghez, A. M., Young, E. F., McKay, C. P., 1999. Titan: High-resolution speckle images from the Keck telescope. Icarus 139, 189-201.

Gibbard, S. G., Macintosh, B., Gavel, D., Max, C. E., de Pater, I., Roe, H. G., Ghez, A. M., Young, E. F., McKay, C. P., 2004a. Speckle imaging of Titan at 2 microns: Surface albedo, haze optical depth, and tropospheric clouds 1996-1998. Icarus 169, 429-439.

Gibbard, S. G., de Pater, I., Macintosh, B. A., Roe, H. G., Max, C. E., Young, E. F., McKay, C. P., 2004b. Titan's $2 \mu \mathrm{m}$ surface albedo and haze optical depth in 1996-2004. Geophys. Res. Let. 31, CiteID L17S02.

Gill, A. E., 1982. Atmosphere-Ocean Dynamics. New York: Academic Press, 1982.

Gillet, F. C, Forrest W. J, Merril K. M., 1973. 8-13 micron observations of Titan. Astrophys. J. 184, L93-L95.

Gillet, F. C., 1975. Further observations of the 8-13 micron spectrum of Titan. Astrophys. J. 201, L41-L43.

Goldstein, R. M., Jurgens, R. F., 1992. DSN observations of Titan. TDAPR 42-109, Jet Propulsion Laboratory.

Grard, R., Hamelin, M., López-Moreno, J. J., Schwingenschuh, K., Jernej, I., Molina-Cuberos, G. J., Simões, F., Trautner, R., Falkner, P., Ferri, F., Fulchignoni, M., Rodrigo, R., Svedhem, H., Béghin, C., Berthelier, J.-J., Brown, V. J. G., Chabassière, M., Jeronimo, J. M., Lara, L. M., Tokano, T., 2006. Electric properties and related physical characteristics of the atmosphere and surface of Titan. Plan. Space Sci. 54, 1124-1136.

Grasset, O., Sotin, C., 1996. The cooling rate of a liquid shell in Titan's interior. Icarus 123, 101-112.

Grasset, O., Sotin, C., Deschamps, F., 2000. On the internal structure and dynamics of Titan. Plan. Space Sci. 48, 617-636.

Grasset, O., Pargamin, J., 2005. The ammonia water system at high pressures: Implications for the methane of Titan. Plan. Space Sci. 53, 371-384.

Greeley, R., Iverson, J. P., 1985. Wind as a geological process on Earth, Mars, Venus, and Titan. Cambridge University Press.

Grieger, B., Lemmon, M. T., Markiewicz, W. J., Keller, H. U., 2003. Inverse radiation modeling of Titan's atmosphere to assimilate solar aureole imager data of the Huygens probe. Plan. Space Sci. 51, 147-158.

Grieger, B., Rodin, A. V., Salinas, S. V., Keller, H. U., 2003. Simultaneous retrieval of optical depths and scattering phase functions in Titan's atmosphere from Huygens/DISR data. Plan. Space Sci. 51, 991-1001.

Grieger, B., 2005. Shading under Titan's sky. Plan. Space Sci. 53, 577-585.

Griffith, C. A., Owen, T., Wagener, R., 1991. Titan's surface and troposphere, investigated with groundbased, near-infrared observations. Icarus 93, 362-378.

Griffith, C. A., 1993. Evidence for surface heterogeneity on Titan. Nature 364, 511-514.

Griffith, C. A., Zahnle, K., 1995. İnflux of cometary volatiles to planetary moons: The atmospheres of 1000 possible Titans. J. Geophys. Res. 100, 16, 907-16, 922.

Griffith, C. A., Owen, T., Miller, G. A., Geballe, T., 1998. Transient clouds in Titan's lower atmosphere. Nature 395, 575-578.

Griffith, Caitlin A., Hall, Joseph L., Geballe, Thomas R., 2000. Detection of daily clouds on Titan. Science 290, 509-513.

Griffith, Caitlin A., Owen, Tobias, Geballe, Thomas R., Rayner, John, Rannou, Pascal, 2003. Evidence for the exposure of water ice on Titan's surface. Science 300, 628-630.

Griffith, C. A., Penteado, P., Greathouse, T. K., Roe, H. G., Yelle, R. V., 2005. Observations of Titan's mesosphere. Astrophys. J. 629, L57-L60. 
Griffith, C. A., Penteado, P., Baines, K., Drossart, P., Barnes, J., Bellucci, G., Bibring, J., Brown, R., Buratti, B., Capaccioni, F., Cerroni, P., Clark, R., Combes, M., Coradini, A., Cruikshank, D., Formisano, V., Jaumann, R., Langevin, Y., Matson, D., McCord, T., Mennella, V., Nelson, R., Nicholson, P., Sicardy, B., Sotin, C., Soderblom, L. A., Kursinski, R., 2005. The Evolution of Titan's mid-latitude clouds. Science 310, 474-477.

Griffith, C. A., Penteado, P., Rannou, P., Brown, R., Boudon, V., Baines, K., Clark, R., Drossart, P., Buratti, B., Nicholson, P., Jaumann, R., McKay, C. P., Coustenis, A., Negrão, A., 2006. Evidence for ethane clouds on Titan from Cassini VIMS observations. Science 313, 1620-1622.

Griffith, G., 2006. Planetary science: Titan's exotic weather. Nature 442, 362-363.

Grossman, A. W., Muhleman, D. O., 1991. Observations of Titan's radio light-curve at $3.5 \mathrm{~cm}$ (abstract) Bull. Am. Astron. Soc. 27, 1104.

Gupta, S., Ochiai, E., Ponnaperuma, C., 1981. Organic synthesis in the atmosphere of Titan. Nature 293, 725-727.

Gurwell, M. A., 2004. Submillimeter observations of Titan: Global measures of stratospheric temperature, CO, HCN, HC3N, and the isotopic ratios $12 \mathrm{C} / 13 \mathrm{C}$ and $14 \mathrm{~N} / 15 \mathrm{~N}$. Astrophys. J. 616, L7-L10.

Gurwell, M. A., Muhleman, D. O., 1995. CO on Titan: Evidence for a well-mixed vertical profile. Icarus 117, 375-382.

Gurwell, M. A., Muhlemann, D. O., 2000. CO on Titan: More evidence for a well-mixed vertical profile. Icarus 145, 653-656.

Hagermann, A., Ball, A. J., Hathi, B., Leese, M. R., Lorenz, R. D., Rosenberg, P. D., Towner, M. C., Zarnecki, J. C., 2006. Inferring the composition of the liquid surface on Titan at the Huygens probe landing site from Surface Science Package measurements. Adv. Space Res. 38, 794-798.

Hagermann, A., Zarnecki, J. C., 2006. Virial treatment of the speed of sound in cold, dense atmospheres and application to Titan. Monthly Notices of the Royal Astronomical Society 368, 321-324.

Hagermann, A., Rosenberg, P. D., Towner, M. C., Garry, J. R. C., Svedhem, H., Leese, M. R., Hathi, B., Lorenz, R. D., Zarnecki, J. C., 2007. Speed of sound measurements and the methane abundance in Titan's atmosphere. Icarus 189, 538-543.

Hall, J. L., Kerzhanovich, V. V., Yavrouian, A. H., Jones, J. A., White, C. V., Dudik, B. A., Plett, G. A., Mennella, J., Elfes, A., 2006. An aerobot for global in situ exploration of Titan. Adv. Space Res. 37, 2108-2119.

Hanel, R., Conrath, B., Flasar, F. M., Kunde, V., Maguire, W., Pearl, J. C., Pirraglia, J., Samuelson, R., Herath, L., Allison, M., Cruikshank, D. P., Gautier, D., Gierasch, P. J., Horn, L., Koppany, R., Ponnamperuma, C., 1981. Infrared observations of the Saturnian system from Voyager 1. Science 212, 192-200.

Hanel, R., Pearl, J. C., Mayo, L. A., 1982. In: Voyager Infrared Interferometer Spectrometer and Radiometer (IRIS). Documentation for Reduced Data Records (RDR) for the Saturnian System, NASA SP X-693-82-30. GSFC, Greenbelt, Maryland 20771.

Hapke, B., 1990. Coherent backscatter and the radar characteristics of the outer planet satellites. Icarus 88, 407-419.

Hapke, B., 1986. On the sputter alteration of regoliths of outer solar system bodies. Icarus $\mathbf{6 6}$, 270-279.

Harri, A.-M., Mäkinen, T., Lehto, A., Kahanpää, H., Siili, T., 2006. Vertical pressure profile of Titan Observations of the PPI/HASI instrument. Plan. Space Sci. 54, 1117-1123.

Hartle, R. E., Sittler, E. C., Neubauer, F. M., Johnson, R. E., Smith, H. T., Crary, F., McComas, D. J., Young, D. T., Coates, A. J., Simpson, D., Bolton, S., Reisenfeld, D., Szego, K., Berthelier, J. J., Rymer, A., Vilppola, J., Steinberg, J. T., Andre, N., 2006. Preliminary interpretation of Titan plasma interaction as observed by the Cassini plasma spectrometer: Comparisons with Voyager 1. Geophys. Res. Let. 33, CiteID L08201.

Hartle, R. E., Sittler, E. C., Neubauer, F. M., Johnson, R. E., Smith, H. T., Crary, F., McComas, D. J., Young, D. T., Coates, A. J., Simpson, D., Bolton, S., Reisenfeld, D., Szego, K., Berthelier, J. J., 
Rymer, A., Vilppola, J., Steinberg, J. T., Andre, N., 2006. Initial interpretation of Titan plasma interaction as observed by the Cassini plasma spectrometer: Comparisons with Voyager 1. Plan. Space Sci. 54, 1211-1224.

Hartung, M., Herbst, T. M., Close, L. M., Lenzen, R., Brandner, W., Marco, O., Lidman, C., 2004a. A new VLT surface map of Titan at 1.575 microns. Astron. Astrophys. 421, L17-L20.

Hartung, M., Herbst, T. M., Dumas, C., Coustenis, A., 2006. Limits to the abundance of $\mathrm{CO}_{2}$ ice on Titan. J. Geophys. Res. Planets 111, E07S09.

Hayashi, C., Nakazawa, K., Nakagawa, Y., 1985 Formation of the Solar System. In: Protostars and Planets II (Black, Matthews, eds.), 1100-1153. University of Arizona Press.

Hébrard, E., Dobrijevic, M., Bénilan, Y., Raulin, F., 2007. Photochemical kinetics uncertainties in modeling Titan's atmosphere: First consequences. Plan. Space Sci. 55, 1470-1489.

Hersant, F., Gautier, D., Lunine, J. I., 2004. Enrichments in volatiles in the giant planets of the solar system. Plan. Space Sci. 52, 623-624.

Herschel, J., 1847. Results of astronomical observations made during the year 1834-8 at the Cape of Good Hope. London.

Hidayat, T., Marten, A., Bézard, B., Gautier, D., Owen, T., Matthews, H. E., Paubert, G., 1997. Millimetre and submillimetre heterodyne observations of Titan: Retrieval of the vertical profile of $\mathrm{HCN}$ and the ${ }^{12} \mathrm{C} /{ }^{13} \mathrm{C}$ Ratio. Icarus 126, $170-182$.

Hidayat, T., Marten, A., Bézard, B., Gautier, D., Owen, T., Matthews, H. E., Paubert, G., 1998. Millimeter and submillimeter heterodyne observations of Titan: The vertical profile of carbon monoxide in its stratosphere. Icarus 133, 1, 109-133.

Hestroffer, D., 2003. Photometry with a periodic grid. II. Results for J2 Europa and S6 Titan. Astron. Astrophys. 403, 749-756.

Hinson, D. P., Tyler, G. L., 1983. Internal gravity waves in Titan's atmosphere observed by Voyager radio occultation. Icarus 54, 337-352.

Hirtzig, M., Coustenis, A., Lai, O., Emsellem, E., Pecontal-Rousset, A., Rannou, P., Negrao, A., Schmitt, B., 2005. Near-infrared study of Titan's resolved disk in spectro-imaging with CFHT/OASIS. Plan. Space Sci. 53, 535-556.

Hirtzig, M., Coustenis, A., Gendron, E., Drossart, P., Negrao, A., Combes, M., Lai, O., Rannou, P., Lebonnois, S., Luz, D., 2006. Monitoring atmospheric phenomena on Titan. Astron. Astrophys. 456, 761-774.

Hirtzig, M., Coustenis, A., Gendron, E., Drossart, P., Hartung, M., Negrao, A., Rannou, Combes, M., 2007. Titan: Atmospheric and surface features as observed with NAOS/CONICA at the time of the Huygens' landing. J. Geophys. Res. Planets 112, E02S91.

Hodyss, R., McDonald, G., Sarker, N., Smith, M. A., Beauchamp, P. M., Beauchamp, J. L., 2004. Fluorescence spectra of Titan tholins: In-situ detection of astrobiologically interesting areas on Titan's surface. Icarus 171, 525-530.

Houghton, J. T., 1986. The Physics of Atmospheres. Cambridge University Press.

Houghton, J. T., Taylor, F. W., Rodgers, C. D., 1986. Remote Sounding of Atmospheres. Cambridge University Press.

Hourdin, F., Talagrand, O., Sadourny, R., Courtin, R., Gautier, D., McKay, C. P., 1995. Numerical simulation of the general circulation of the atmosphere of Titan. Icarus 117, 358-374.

Hourdin, F., Lebonnois, S., Luz, D., Rannou, P., 2004. Titan's stratospheric composition driven by condensation and dynamics. J. Geophys. Res. 109, CiteID E12005.

Hubbard, W. B., Hunten, D. M., Reitsema, H. J. Brosch, N., Nevo, Y., Carreira, E., Rossi, F., Wasserman, L. H., 1990. Results of Titan's atmosphere from its occultation of 28 Sagittari. Nature 343, 353-355.

Hubbard, W. B., Porco, C. C., Hunten, D. M., Rieke, G. H., Rieke, M. J., McCarthy, D. W., Haemmerle, V., Clark, R., Turtle, E. P., Haller, J., McLeod, B., Lebofsky, L. A., Marcialis, R., Holberg, J. B., Landau, R., Carrasco, L., Elias, J., Buie, M. W., Persson, S. E., Boroson, T., West, S., Mink, D. J., 1993. The occultation of 28 Sgr by Titan. Astron. Astrophys. 269, 541-563. 
Hudson, R. L., Moore, M. H., 2004. Reactions of nitriles in ices relevant to Titan, comets, and the interstellar medium: Formation of cyanate ion, ketenimines, and isonitriles. Icarus 172, 466-478.

Hueso, R., Sánchez-Lavega, A., 2006. Methane storms on Saturn's moon Titan. Nature 442, 428-431.

Hunten, D. M., 1977. Titan's atmosphere and surface. In: Planetary Satellites (Burns, J. A., ed.) Tucson: Univ. of Arizona Press, pp. 420-437.

Hunten, D. M., Tomasko, M. G, Flasar, F. M, Samuelson, R. E., Strobel, D. F., Stevenson, D. J., 1984. Titan. In: Saturn (Gehrels, T., Matthews, M., eds.), 671-759. University of Arizona Press.

Hunten, D. M., 2006. The sequestration of ethane on Titan in smog particles. Nature 443, 669-670.

Hutzell, W. T., McKay, C. P., Toon, O. B., 1993. Effects of time-varying haze production on Titan's geometric albedo. Icarus 105, 162-174.

Hutzell, W. T., McKay, C. P., Toon, O. B., Hourdin, F., 1996. Simulations of Titan's brightness by a two-dimensional haze model. Icarus 119, 112-129.

Huygens, C., 1659. Systema Saturnium.

Huygens, C., 1698. The Celestial Worlds Discover'd.

Huygens, C., 1888-1950. Oeuvres completes de Christiaan Huygens, 22 Vols. Martinus Nijhoff, The Hague.

Imanaka, H., Khare, B. N., Elsila, J. E., Bakes, E. L. O., McKay, C. P., Cruikshank D. P., Sugita, S., Matsui, T., Zare, R. N., 2004. Laboratory experiments of Titan tholin formed in cold plasma at various pressures: Implications for nitrogen-containing polycyclic aromatic compounds in Titan haze. Icarus 168, 344-366.

Imanaka, H., Smith, M. A., 2007. Role of photoionization in the formation of complex organic molecules in Titan's upper atmosphere. Geophys. Res. Let. 34, CiteID L02204.

Israel, G., Cabane, M., Raulin, F., Chassefière, E., Boon, J. J., 1991. Aerosols in Titan's atmosphere: Models, sampling techniques and chemical analysis Ann. Geophys. 9, 1-13.

Israël, G., Szopa, C., Raulin, F., Cabane, M., Niemann, H. B., Atreya, S. K., Bauer, S. J., Brun, J.-F., Chassefière, E., Coll, P., Condé, E., Coscia, D., Hauchecorne, A., Millian, P., Nguyen, M.-J., Owen, T., Riedler, W., Samuelson, R. E., Siguier, J.-M., Steller, M., Sternberg, R., Vidal-Madjar, C., 2005. Complex organic matter in Titan's atmospheric aerosols from in situ pyrolysis and analysis. Nature 438, 796-799.

Jaffe, W., Caldwell, J., Owen, T., 1979. The brightness of Titan at 6 centimetres from the Very Large Array. Astrophys. J. 232, L75-L76.

Jacquinet-Husson, N., Scott, N. A., Chédin, A., Crépeau, L., Armante, R., Capelle, V., Orphal, J., Coustenis, A., Barbe, A., Birk, M., Brown, L. R., and 40 co-authors, 2008. The GEISA spectroscopic database: Current and future archive for Earth's planetary atmosphere studies. JQSRT, in press.

Jaumann, R., Stephan, K., Brown, R. H., Buratti, B. J., Clark, R. N., McCord, T. B., Coradini, A., Capaccioni, F., Filacchione, G., Cerroni, P., Baines, K. H., Bellucci, G., Bibring, J.-P., Combes, M., Cruikshank, D. P., Drossart, P., Formisano, V., Langevin, Y., Matson, D. L., Nelson, R. M., Nicholson, P. D., Sicardy, B., Sotin, C., Soderbloom, L. A., Griffith, C., Matz, K.-D., Roatsch, Th., Scholten, F., Porco, C. C., 2006. High-resolution CASSINI-VIMS mosaics of Titan and the icy Saturnian satellites. Plan. Space Sci. 54, 1146-1155.

Jones, T. D., Lewis, J. S., 1987. Estimated impact shock production of $\mathrm{N}_{2}$ and organic compounds on early Titan. Icarus 72, 381-393.

Justus, C. G., Duvall, A., Keller, V. W., Spilker, T. R., Kae Lockwood, M., 2005. Connecting atmospheric science and atmospheric models for aerocapture at Titan and the outer planets. Plan. Space Sci. 53, 601-605.

Kabin, K., Gombosi, T. I., De Zeeuw, D. L., Powell, K. G., Israelevich, P. L., 1999. Interaction of the Saturnian magnetosphere with Titan: Results of a three-dimensional MHD simulation. J. Geophys. Res. 104, 2451-2458.

Kabin, K., Israelevich, P. L., Ershkovich, A. I., Neubauer, F. M., Gombosi, T. I., De Zeeuw, D. L., Powell, K. G., 2000. Titan's magnetic wake: Atmospheric or magnetospheric interaction. J. Geophys. Res. 105, 10761-10770. 
Kallio, E., Sillanpää, I., Janhunen, P., 2004. Titan in subsonic and supersonic flow. Geophys. Res. Let. 31, CiteID L15703.

Karatekin, Ö., Van Hoolst, T., 2006. The effect of a dense atmosphere on the tidally induced potential of Titan. Icarus 183, 230-232.

Karkoschka, E., Lorenz, R. D., 1997. Latitudinal variation of aerosol sizes inferred from Titan's shadow. Icarus 125, 369-379.

Kazeminejad, B., Lammer, H., Coustenis, A., Fischer, G., Schwingenschuh, K., Rucker, H. O., 2005. Temperature variations in Titan's upper atmosphere: Impact on Cassini/Huygens. Ann. Geophys. 23, 1183-1189.

Keller, C. N., Anicich, V. G., Cravens T. E., 1998. Model of Titan's ionosphere with detailed hydrocarbon chemistry. Planet. Space Sci. 46, 1157-1174.

Khanna, R. K., Perera-Jarmer, M. A., Ospina, M. J., 1987. Vibrational infared and Raman spectra of dicyanoacetylene. Spectroch. Acta 43A, 421-425.

Khanna, R. K., 2005. Condensed species in Titan's stratosphere: Identification of crystalline propionitrile $\left(\mathrm{C}_{2} \mathrm{H}_{5} \mathrm{CN}, \mathrm{CH}_{3} \mathrm{CH}_{2} \mathrm{CN}\right)$ based on laboratory infrared data. Icarus 177, 116-121.

Khanna, R. K., 2005. Condensed species in Titan's stratosphere: Confirmation of crystalline cyanoacetylene $\left(\mathrm{HC}_{3} \mathrm{~N}\right)$ and evidence for crystalline acetylene $\left(\mathrm{C}_{2} \mathrm{H}_{2}\right)$ on Titan. Icarus 178, $165-170$.

Khanna, R. K., 2007. Corrigendum to "Condensed species in Titan's stratosphere: Confirmation of crystalline cyanoacetylene $\left(\mathrm{HC}_{3} \mathrm{~N}\right)$ and evidence for crystalline acetylene $\left(\mathrm{C}_{2} \mathrm{H}_{2}\right)$ on Titan" [Icarus 178 (2005) 165-170]. Icarus 186, 589-589.

Khare, B. N., Sagan, C., Zumberge, J. F., Sklarew, D. S., Nagy, A., 1982. Organic solids produced by electrical discharge in reducing atmospheres: Tholin molecular analysis. Icarus 48, 290-297.

Khare, B. N., Sagan, C., Thompson, W. R., 1987. Solid hydrocarbon aerosols produced in simulated Uranian and Neptunian stratosphere. J. Geophys. Res. 92, 15, 067-15, 082.

Khare, B. N., Sagan, C. Arakawa, E. T. Suits, F., Callcott,T. A., Williams, M. W., 1984. Optical constants of organic tholins produced in a simulated Titanian atmosphere: From soft X-ray to microwave frequencies. Icarus 60, 127-137.

Khare, B. N., Sagan, C., Ogino, H., Nagy, B., Er. C., Schram, K. H., Arakawa, E. T., 1986. Amino acids derived from Titan tholins. Icarus 68, 176-184.

Khare, B. N., Sagan, C., Thompson, W. R., Arakawa, E. T., Suits, F, Callcott, T. A., Williams, M. W., Shrader, S., Ogino, H., Willingham, T. O., Nagy, B., 1984. The organic aerosols of Titan. Adv. Space Res. 4, 59-68.

Khare, Bishun N., Bakes, E. L. O., Imanaka, Hiroshi, McKay, Christopher P., Cruikshank, Dale P., Arakawa, Edward T., 2002. Analysis of the time-dependent chemical evolution of Titan haze tholin. Icarus 160, Issue 1, pp. 172-182.

Kim, S. J., King, W. T. 1984. Integrated infrared intensities in cyanogen. J. Chem. Phys. 80, 974-977.

Kim, S. J, Caldwell, J., 1982 The Abundance of $\mathrm{CH}_{3} \mathrm{D}$ in the Atmosphere of Titan derived from 8 to $14 \mathrm{~mm}$ thermal emission. Icarus 52, 473-482.

Kim, S. J., Geballe, T. R., Noll, Keith S., 2000. NOTE: Three-micrometer $\mathrm{CH}_{4}$ line emission from Titan's high-altitude atmosphere. Icarus 147, 588-591.

Kim, S. J., Lee, Y. S., Kim, Y. H., 2001. Spectroscopic studies of the atmospheres of giant planets, Titan, and comets. Plan. Space Sci. 49, 117-141.

Kopp, A., Ip, W.-H., 2001. Asymmetric mass loading effect at Titan's ionosphere. J. Geophys. Res. 106, 8323-8332.

Korycansky, D. G., Zahnle, K. J., 2005. Modeling crater populations on Venus and Titan. Plan. Space Sci. 53, 695-710.

Kostiuk, T., Fast, K. E., Livengood, T. A., Hewagama, T., Goldstein, J. J., Espenak, F., Buhl, D., 2001. Direct measurement of winds of Titan. Geophys. Res. Let. 28, 2361-2364.

Kostiuk, T., Livengood, T. A., Hewagama, T., Sonnabend, G., Fast, K. E., Murakawa, K., Tokunaga, A. T., Annen, J., Buhl, D., Schmülling, F., 2005. Titan's stratospheric zonal wind, 
temperature, and ethane abundance a year prior to Huygens insertion. Geophys. Res. Let. 32, CiteID L22205.

Kostiuk, T., Livengood, T. A., Sonnabend, G., Fast, K. E., Hewagama, T., Murakawa, K., Tokunaga, A. T., Annen, J., Buhl, D., Schmülling, F., Luz, D., Witasse, O., 2006. Stratospheric global winds on Titan at the time of Huygens descent. J. Geophys. Res. 111, CiteID E07S03.

Kress, M. E., McKay, C. P., 2004. Formation of methane in comet impacts: Implications for Earth, Mars, and Titan. Icarus 168, 475-483.

Krimigis, S. M., Armstrong, T. P., Axford, W. I., Bostrom, C. O., Gloeleckler, G., Keath, E. P., Lanzerotti, L. J., Carbarry, J. F., Hamilton, D. C., Roelof, E. C., 1982. Low energy hot plasma and particles in Saturn's magnetosphere. Science 215, 571-577.

Kuiper, G. P., 1944. Titan: A satellite with an atmosphere. Astrophys J., 100, 378-383.

Kunde, V. G., Aikin, A. C., Hanel, R. A., Jennings, D. E., Maguire, W. C., Samuelson, R. E., 1981. $\mathrm{C}_{4} \mathrm{H}_{2}, \mathrm{HC}_{3} \mathrm{~N}$ and $\mathrm{C}_{2} \mathrm{~N}_{2}$ in Titan's atmosphere, Nature 292, 686-688, 1981.

Lammer, H., Stumptner, W., 1999. High altitude haze: Influence of monomer particles on Titan's temperature profile. Plan. Space Sci. 47, 1341-1346.

Lammer, H., Stumptner, W., Molina-Cuberos, G. J., Bauer, S. J., Owen, T., 2000. Nitrogen isotope fractionation and its consequence for Titan's atmospheric evolution. Plan. Space Sci. 48, 529-543.

Lammer, H., Tokano, T., Fischer, G., Stumptner, W., Molina-Cuberos, G. J., Schwingenschuh, K., Rucker, H. O., 2001. Plan. Space Sci. 49, 561-574.

Lara, L. M., Lorenz, R. D., Rodrigo, R., 1994. Liquids and solids on the surface of Titan. Planet. Space Sci. 42, 5-14.

Lara, L. M., Lellouch, E., López-Moreno, J. J, Rodrigo, R., 1996. Vertical distribution of Titan's atmospheric neutral constituents. J. Geophys. Res. 101, 23262-23283.

Lara, L.-M., Lellouch, E., Shematovich, V., 1999. Titan's atmospheric haze: The case for HCN incorporation. Astron. Astrophys. 341, 312-317.

Lara, L. M., Banaszkiewicz, M., Rodrigo, R., Lopez-Moreno, J. J., 2002. The CH4 density in the upper atmosphere of Titan. Icarus 158, 191-198.

Lavvas, P. P., Coustenis, A., Vardavas, I. M., 2007a. Coupling photochemistry with haze formation in Titan's atmosphere. Part I: Model description. Plan. Space Sci., in press.

Lavvas, P. P., Coustenis, A., Vardavas, I. M., 2007b. Coupling photochemistry with haze formation in Titan's atmosphere. Part II: Results and validation with Cassini/Huygens data. Plan. Space Sci., in press.

Lebonnois, S., Toublanc, D., 1999. Actinic fluxes in Titan's atmosphere, from one to three dimensions: Application to high-latitude composition. J. Geophys. Res. 104, 22025-22034.

Lebonnois, S., Toublanc, D., Hourdin, F., Rannou, P., 2001. Seasonal variations of Titan's atmospheric composition. Icarus 152, 384-406.

Lebonnois, S., Bakes, E. L. O., McKay, C. P., 2002. Transition from gaseous compounds to aerosols in Titan's atmosphere. Icarus 159, 505-517.

Lebonnois, S., Bakes, E. L. O., McKay, C. P., 2003a. Atomic and molecular hydrogen budget in Titan's atmosphere. Icarus 161, 474-485.

Lebonnois, S., Hourdin, F., Rannou, P., Luz, D., Toublanc, D., 2003b. Impact of the seasonal variations of composition on the temperature field of Titan's stratosphere. Icarus 163, 164-174.

Lebonnois, S., 2005. Benzene and aerosol production in Titan and Jupiter's atmospheres: A sensitivity study. Plan. Space Sci. 53, 486-497.

Lebreton, J.-P., Witasse, O., Sollazzo, C., Blancquaert, T., Couzin, P., Schipper, A.-M., Jones, J. B., Matson, D. L., Gurvits, L. I., Atkinson, D. H., Kazeminejad, B., Pérez-Ayúcar, M., 2005. An overview of the descent and landing of the Huygens probe on Titan. Nature 438, 758-764.

Lécluse, C., Robert, F., 1994. Hydrogen isotope exchange rates: Origin of water in the inner Solar System. Geochim. Cosmochim. Acta 58, 2297-2939.

Lécluse, C., Robert, F., Gautier, D., Guiraud, M., 1996. Deuterium enrichment in giant planets. Plan. Space Sci. 44, 1579-1592. 
Ledvina, Stephen A., Brecht, Stephen H., Luhmann, Janet G., 2004. Ion distributions of 14 amu pickup ions associated with Titan's plasma interaction. Geophys. Res. Let. 31, CiteID L17S10.

Ledvina, S. A., Cravens, T. E., Kecskeméty, K., 2005. Ion distributions in Saturn's magnetosphere near Titan. J. Geophys. Res. 110, CiteID A06211.

Lellouch, E., Coustenis, A., Gautier, D., Raulin, F., Dubouloz, N., Frère, C., 1989. Titan's atmosphere and hypothesized ocean: A reanalysis of the Voyager 1 radio-occultation and IRIS $7.7 \mu \mathrm{m}$ data. Icarus 79, 328-349.

Lellouch, E., Hunten, D., Kockarts, G., Coustenis, A., 1990. Titan's thermosphere profile. Icarus 83, 308-224.

Lellouch, E., Coustenis, A., Sebag, B., Cuby, J.-G., Lopez-Valverde, M., Fouchet, T., Crovisier, J., Schmitt, B., 2003. Titan's 5-micron window: Observations with the very large telescope. Icarus 162, 125-142.

Lellouch, E., Schmitt, B., Coustenis, A., Cuby, J.-G. 2004. Titan's 5-micron lightcurve. Icarus 168, 209-214.

Lemmon, M. T., Karkoschka E., Tomasko, M., 1993. Titan's rotation: Surface feature observed. Icarus 103, 329-332.

Lemmon, M. T., Karkoshka, E., Tomasko, M., 1995. Titan's rotational lightcurve. Icarus 113, $27-38$.

Lemmon, M. T., Smith, P. H., Lorenz, R. D., 2002. Methane abundance on Titan, measured by the space telescope imaging spectrograph. Icarus 160, 375-385.

Letourneur, B., Coustenis, A., 1993. Titan's atmospheric structure from Voyager 2 infrared spectra. Planet. Space Sci. 41, 593-602.

Levine, J. S. (ed.), 1985. Photochemistry of Atmospheres. New York: Academic Press.

Lewis. J. S., 1998. Physics and Chemistry of the Solar System. Academic Press, Second edition.

Liang, M.-C., Heays, A. N., Lewis, B. R., Gibson, S. T., Yung, Y. L., 2007. Source of nitrogen isotope anomaly in HCN in the atmosphere of Titan. Astrophys. J. 664, L115-L118.

Liang, M.-C., Yung, Y. L., Shemansky, D. E., 2007. Photolytically generated aerosols in the mesosphere and thermosphere of Titan. Astrophys. J. 661, L199-L202.

Lilensten, J., Simon, C., Witasse, O., Dutuit, O., Thissen, R., Alcaraz, C., 2005. A fast computation of the diurnal secondary ion production in the ionosphere of Titan. Icarus 174, 285-288.

Lilensten, J., Witasse, O., Simon, C., Soldi-Lose, H., Dutuit, O., Thissen, R., Alcaraz, C., 2005. Prediction of a $\mathrm{N}_{2}^{++}$layer in the upper atmosphere of Titan. Geophys. Res. Let. 32, CiteID L03203.

Lindal, G. F., Wood, G. E., Hotz, H. B., Sweetnam, D. N., Eshelman, V. R., Tyler, G. L., 1983. The atmosphere of Titan: An analysis of the Voyager 1 radio-occultation measurements. Icarus 53, 348-363.

Livengood, T. A., Hewagama, T., Kostiuk, T., Fast, K. E., Goldstein, J. J., 2002. Improved determination of ethane $\left(\mathrm{C}_{2} \mathrm{H}_{6}\right)$ abundance in Titan's stratosphere. Icarus 157, 249-253.

Livengood, T. A., Kostiuk, T., Sonnabend, G., Annen, J. N., Fast, K. E., Tokunaga, A., Murakawa, K., Hewagama, T., Schmülling, F., Schieder, R., 2006. High-resolution infrared spectroscopy of ethane in Titan's stratosphere in the Huygens epoch. J. Geophys. Res. 111, CiteID E11S90.

Lopes, R. M. C., Mitchell, K. L., Stofan, E. R., Lunine, J. I., Lorenz, R., Paganelli, F., Kirk, R. L., Wood, C. A., Wall, S. D., Robshaw, L. E., Fortes, A. D., Neish, C. D., Radebaugh, J., Reffet, E., Ostro, S. J., Elachi, C., Allison, M. D., Anderson, Y., Boehmer, R., Boubin, G., Callahan, P., Encrenaz, P., Flamini, E., Francescetti, G., Gim, Y., Hamilton, G., Hensley, S., Janssen, M. A., Johnson, W. T. K., Kelleher, K., Muhleman, D. O., Ori, G., Orosei, R., Picardi, G., Posa, F., Roth, L. E., Seu, R., Shaffer, S., Soderblom, L. A., Stiles, B., Vetrella, S., West, R. D., Wye, L., Zebker, H. A., 2007. Cryovolcanic features on Titan's surface as revealed by the Cassini Titan Radar Mapper. Icarus 186, 395-412.

Lopez-Valverde, M. A., Lellouch, E., Coustenis, A., 2005. Carbon monoxide fluorescence from Titan's atmosphere. Icarus 175, 503-521. 
Lorenz, R. D., 1996. Pillow Lava on Titan: Expectations and constraints on cryovolcanic processes. Planet. Space Sci. 44(9), 1021-1028.

Lorenz, R. D., 2002. Thermodynamics of geysers: Application to Titan. Icarus 156, 176-183.

Lorenz, R. D., 2001. Erratum: "Titan, Mars and Earth: Entropy production by latitudinal heat transport”. Geophys. Res. Let. 28, 3169-3170.

Lorenz, R. D., Zarnecki, J. C., 1992. Precipitation on Titan and the methane icing hazard to the Huygens descent probe. Ann. Geophys. 10(3), C487.

Lorenz, R. D., 1993a. The life, death, afterlife of a raindrop on Titan. Planet. Space Sci. 41(9), 647-655.

Lorenz, R. D., 1993b. Raindrops on Titan. Adv. Space Res. 15(3), 317-320.

Lorenz, R. D., 1994. Crater lakes on Titan: Rings, horseshoes and bullseyes. Planet. Space Sci. 42(1), 1-4.

Lorenz, R. D., Lunine, J. I., Grier, J. A., Fisher, M. A., 1995. Predicting Aeolian activity on planets: Application to Titan palaeoclimatology. J. Geophys. Res. 100, 26377-26386.

Lorenz, R. D., Lunine, J. I., 1996. Erosion on Titan: Past and Present. Icarus 122, 79-91.

Lorenz, R. D., Smith, P. H., Lemmon, M. T., Karkoschka, E, Lockwood, G. W., Caldwell, J. D., 1997a. Titan's north south asymmetry from Hubble space telescope and voyager imaging: Comparison with models and ground based photometry. Icarus 127, 173-189.

Lorenz, R. D., McKay, C. P., Lunine, J. I., 1997b. Photochemically-induced collapse of Titan's atmosphere. Science 275, 642-644.

Lorenz, R. D., Lemmon, M. T., Smith, P. H., Lockwood, G. W., 1999a. Seasonal change on Titan observed with the Hubble space telescope WFPC-2. Icarus 142, 391-401.

Lorenz, R. D., McKay, C. P., Lunine, J. I., 1999b. Analytic investigation of climate stability on Titan: Sensitivity to volatile inventory. Plan. Space Sci. 47, 1503-1515.

Lorenz, R. D., Shandera, S. E., 2001a. Physical properties of ammonia-rich ice: Application to Titan. Geophys. Res. Let. 28, 215-218.

Lorenz, R. D., Lunine, J. I., Withers, P. G., McKay, C. P., 2001b. Titan, Mars and Earth: Entropy production by latitudinal heat transport. Geophys. Res. Let. 28, 415-418.

Lorenz, R. D., Young, E. F., Lemmon, M. T., 2001. Titan's smile and collar: HST observations of Seasonal Change 1994-2000. Geophys. Res. Let. 28, 4453-4456.

Lorenz, R. D., Lunine, J. I., 2002. Titan's snowline. Icarus 158, 557-559.

Lorenz, R. D., Dooley, J. M., West, J. D., Fujii, M., 2003. Backyard spectroscopy and photometry of Titan, Uranus and Neptune. Plan. Space Sci. 51, 113-125.

Lorenz, R. D., Biolluz, G., Encrenaz, P., Janssen, M. A., West, R. D., Muhleman, Duane O., 2003. Cassini RADAR: Prospects for Titan surface investigations using the microwave radiometer. Plan. Space Sci. 51, 353-364.

Lorenz, R. D., Smith, P. H., Lemmon, M. T., 2004. Seasonal change in Titan's haze 1992-2002 from Hubble Space Telescope observations. Geophys. Res. Let. 31, Issue 10, CiteID L10702.

Lorenz, R. D., Griffith, C. A., Lunine, J. I., McKay, C. P., Rennò, N. O., 2005. Convective plumes and the scarcity of Titan's clouds. Geophys. Res. Let. 32, Issue 1, CiteID L01201.

Lorenz, R. D., Lunine, J. I., 2005. Titan's surface before Cassini. Plan. Space Sci. 53, 557-576.

Lorenz, R. D., Kraal, E. R., Eddlemon, E. E., Cheney, J., Greeley, R., 2005. Sea-surface wave growth under extraterrestrial atmospheres: Preliminary wind tunnel experiments with application to Mars and Titan. Icarus 175, 556-560.

Lorenz, R. D., Wall, S., Radebaugh, J., Boubin, G., Reffet, E., Janssen, M., Stofan, E., Lopes, R., Kirk, R., Elachi, C., Lunine, J., Mitchell, K., Paganelli, F., Soderblom, L., Wood, C., Wye, L., Zebker, H., Anderson, Y., Ostro, S., Allison, M., Boehmer, R., Callahan, P., Encrenaz, P., Ori, G. G., Francescetti, G., Gim, Y., Hamilton, G., Hensley, S., Johnson, W., Kelleher, K., Muhleman, D., Picardi, G., Posa, F., Roth, L., Seu, R., Shaffer, S., Stiles, B., Vetrella, S., Flamini, E., West, R., 2006. The sand seas of Titan: Cassini RADAR observations of longitudinal dunes. Science 312, 724-727. 
Lorenz, R. D., 2006. Thermal interactions of the Huygens probe with the Titan environment: Constraint on near-surface wind. Icarus 182, 559-566.

Lorenz, Ralph D., Lemmon, Mark T., Smith, Peter H., 2006. Seasonal evolution of Titan's dark polar hood: Midsummer disappearance observed by the Hubble Space Telescope. Monthly Notices of the Royal Astronomical Society 369, 1683-1687.

Lorenz, R. D., Wood, C. A., Lunine, J. I., Wall, S. D., Lopes, R. M., Mitchell, K. L., Paganelli, F., Anderson, Y. Z., Wye, L., Tsai, C., Zebker, H., Stofan, E. R., 2007. Titan's young surface: Initial impact crater survey by Cassini RADAR and model comparison. Geophys. Res. Let. 34, CiteID L07204.

Loveday, J. S., Nelmes, R. J., Guthrie, M., Belmonte, S. A., Allan, D. R., Klug, D. D., Tse, J. S., Handa, Y. P., 2001. Stable methane hydrate above 2GPa and the source of Titan's atmospheric methane. Nature 410, 661-663.

Luna, H., Michael, M., Shah, M. B., Johnson, R. E., Latimer, C. J., McConkey, J. W., 2003. Dissociation of $\mathrm{N} 2$ in capture and ionization collisions with fast $\mathrm{H}^{+}$and $\mathrm{N}^{+}$ions and modeling of positive ion formation in the Titan atmosphere. J. Geophys. Res. (Planets) 108, 14-1.

Lunine, J. I., 1989. The Urey prize lecture: Volatile processes in the outer solar system. Icarus $\mathbf{8 1}$, $1-13$.

Lunine, J. I., 1993. Does Titan have an ocean? A review of current understanding of Titan's surface. Rev. of Geophys. 31, 133-149.

Lunine, J. I., Stevenson, D. J., Yung, Y. L. 1983. Ethane ocean on Titan, Science 222, $1229-1230$.

Lunine, J., Tittemore, W. C., 1983. Origins of outer-planet satellites. In: Protostars and Planets III (Levy and Lunine, eds.), University of Arizona Press, 1177-1252.

Lunine, J. I., Stevenson, D. J., 1985. Evolution of Titan's coupled ocean-atmosphere system and interaction of ocean with bedrock. In: Ices in the Solar System (Klinger, J., Benest, D., Dollfus, A., Smoluchowski, R., eds.), Dordrecht: D. Reidel 741-757.

Lunine, J. I., Stevenson, D. J., 1987. Clathrate and ammonia hydrates at high pressure: Application to the origin of methane on Titan. Icarus 70, 61-77.

Lunine, J. I., Rizk, B., 1989. Thermal evolution of Titan's atmosphere. Icarus 80, 370-389.

Lunine, J. I., Atreya, S. K., Pollack., J. B., 1989. Present state and chemical evolution of the atmospheres of Titan, Triton, and Pluto. In: Origin and evolution of planetary and satellite atmospheres (Atreya, S. K., Pollack, J. B., Matthews, M. S., eds.), Tucson: University of Arizona Press, 605.

Lunine, J., Tittemore, W. C., 1993. Origins of outer-planet satellites. In: Protostars and Planets III (Levy, Lunine, eds.), 1177-1252. University of Arizona Press.

Lunine, J. I., McKay, C. P., 1995 Surface-atmosphere interactions on Titan compared with those on the pre-biotic Earth. Adv. Space Res. 15(3), 303-311.

Lunine, J. I., Lorenz, R. D., Hartmann, W. K., 1998. Some speculation about Titan's past, present, and future. Planet. Space Sci. 46, 1099-1108.

Lunine, J. I., Yung, Y. L., Lorenz, R. D., 1999. On the volatile inventory of Titan from isotopic abundances in nitrogen and methane. Plan. Space Sci. 47, 1291-1303.

Lutz, B. L., de Bergh, C., Owen, T., 1983.Titan: Discovery of carbon monoxide in its atmosphere. Science 220, 1374-1375.

Lutz, B. L., De Bergh, C., Maillard, J. P., Owen, T., Brault, J., 1981. On the possible detection of $\mathrm{CH}_{3} \mathrm{D}$ on Titan and Uranus. Astrophys. J. 248, L141-L145.

Lutz, B. L., Owen, T., Cess, R. D., 1976. Laboratory band strengths of methane and their application to the atmospheres of Jupiter, Saturn, Uranus, Neptune and Titan. Astron. Astrophys. J. 203, $541-551$.

Lutz, B. L., Owen, T., Cess, R. D., 1982. Laboratory band strengths of methane and their application to the atmospheres of Jupiter, Saturn, Uranus, Neptune and Titan. Astron. Astrophys. J. 258, 886-898. 
Luz, D., Hourdin, F., Rannou, P., Lebonnois, S., 2003a. Latitudinal transport by barotropic waves in Titan's stratosphere. I. General properties from a horizontal shallow-water model. Icarus 166, 328-342.

Luz, D., Hourdin, F., Rannou, P., Lebonnois, S., 2003b. Latitudinal transport by barotropic waves in Titan's stratosphere. II. Results from a coupled dynamics-microphysics-photochemistry GCM. Icarus 166, 343-358.

Luz, D., Civeit, T., Courtin, R., Lebreton, J.-P., Gautier, D., Rannou, P., Kaufer, A., Witasse, O., Lara, L., Ferri, F., 2005. Characterization of zonal winds in the stratosphere of Titan with UVES. Icarus 179, 497-510.

Luz, D., Civeit, T., Courtin, R., Lebreton, J.-P., Gautier, D., Witasse, O., Kaufer, A., Ferri, F., Lara, L., Livengood, T., Kostiuk, T., 2006. Characterization of zonal winds in the stratosphere of Titan with UVES: 2. Observations coordinated with the Huygens Probe entry. J. Geophys. Res. 111, CiteID E08S90.

Ma, Y.-J., Nagy, A. F., Cravens, T. E., Sokolov, I. V., Clark, J., Hansen, K. C., 2004. 3-D global MHD model prediction for the first close flyby of Titan by Cassini. Geophys. Res. Let. 31, CiteID L22803.

Ma, Y., Nagy, A. F., Cravens, Th. E., Sokolov, I. V., Hansen, K. C., Wahlund, J.-E., Crary, F. J., Coates, A. J., Dougherty, M. K., 2006. Comparisons between MHD model calculations and observations of Cassini flybys of Titan. J. Geophys. Res. 111, CiteID A05207.

Maguire, W. C., Hanel, R. A., Jennings, D. E., Kunde, V. G., Samuelson, R. E., 1981. $\mathrm{C}_{3} \mathrm{H}_{8}$ and $\mathrm{C}_{3} \mathrm{H}_{4}$ in Titan's atmosphere. Nature 292, 683-686.

Mahaffy, P. R., Donahue, T. M., Atreya, S. K., Owen, T. C., Niemann, H. B., 1998. Galileo probe measurements of D/H and ${ }^{3} \mathrm{He} /{ }^{4} \mathrm{He}$ in Jupiter's atmosphere. Space Sci. Rev. 84, 251-263.

Mahaffy, P. R., 2005. Intensive Titan exploration begins. Science 308, 969-970.

Makalkin, A. B., Dorofeeva, V. A., 2006. Models of the protosatellite disk of Saturn: Conditions for Titan's formation. Solar System Research 40, 441-455.

Mäkinen, J. Teemu T., Harri, A.-M., Tokano, T., Savijärvi, H., Siili, T., Ferri, F., 2006. Vertical atmospheric flow on Titan as measured by the HASI instrument on board the Huygens probe. Geophys. Res. Let. 33, CiteID L21803.

Marten, A., Gautier, D., Tanguy, L., Lecacheux, A., Rosolen, C., Paubert, G., 1988. Abundance of carbon monoxide in the stratosphere of Titan from millimeter heterodyne observations, Icarus 76, 558-562, 1988.

Marten, A., Hidayat, T., Moreno, R., Paybert, G., Bézard, B., Gautier, D., Owen, T., 1997. Saturn VI (Titan). IAU Circular 6702, 19 July.

Marten, A., Hidayat, T., Biraud, Y., Moreno, R., 2002. New millimeter heterodyne observations of Titan: Vertical distributions of Nitriles $\mathrm{HCN}, \mathrm{HC}_{3} \mathrm{~N}, \mathrm{CH}_{3} \mathrm{CN}$, and the isotopic ratio ${ }^{15} \mathrm{~N} /{ }^{14} \mathrm{~N}$ in its atmosphere. Icarus 158, 532-544.

Mayo, L. A., Samuelson, R. E., 2005. Condensate clouds in Titan's north polar stratosphere. Icarus 176, 316-330.

Mayor, M., Queloz, D., 1995. A Jupiter-mass companion to a solar-type star. Nature 378, 355-259.

McCord, T. B., Hansen, G. B., Buratti, B. J., Clark, R. N., Cruikshank, D. P., D’Aversa, E., Griffith, C. A., Baines, E. K. H., Brown, R. H., Dalle Ore, C. M., Filacchione, G., Formisano, V., Hibbitts, C. A., Jaumann, R., Lunine, J. I., Nelson, R. M., Sotin, C., the Cassini VIMS Team, 2006. Composition of Titan's surface from Cassini VIMS. Plan. Space Sci. 54, 1524-1539.

McDonald, G. D., Thompson, W. R., Heinrich, M., Khare, B. N., Sagan, C., 1994. Chemical investigation of Titan and Triton tholins. Icarus 108, 137-145.

McDonough, T., Brice, N., 1973. A Saturnian gas ring and the recycling of Titan's atmosphere. Icarus 20, 136-145.

McGrath, M. A., Courtin, R., Smith, T. E., Feldman, P. D., Strobel, D. F., 1998. The ultraviolet albedo of Titan. Icarus 131, 382-392. 
McKay, C. P., Pollack, J. B., Courtin, R., 1989. The thermal structure of Titan's atmosphere, Icarus 80, 23-53.

McKay, C. P., Pollack, J. B., Courtin, R., 1991. The greenhouse and anti-greenhouse effects on Titan. Science 253, 1118-1121.

McKay, C. P, Pollack, J. B., Lunine, J. I., Courtin, R., 1993. Coupled atmosphere-ocean models of Titan's past. Icarus 102, 88-98.

McKay, C. P., 1996. Elemental composition, solubility, and optical properties of Titan's organic haze, Planet. Space Sci. 44, 8, 741-747.

McKay, C. P., Martin, S. C., Griffin, C. A., Keller, R. M., 1997. Temperature lapse rate and methane in Titan's troposphere. Icarus 129, 498-505.

McKay, C. P., Lorenz, R. D., Lunine, J. I., 1999. Analytic solutions for the antigreenhouse effect: Titan and the early earth. Icarus 137, 56-61.

McKay, C. P., Coustenis, A., Samuelson, R. E., Lemmon, M. T., Lorenz, R. D., Cabane, M., Rannou, P., Drossart, P., 2001. Physical properties of the organic aerosols and clouds on Titan. Plan. Space Sci. 49, 79-99.

McKay, C. P., Smith, H. D., 2005. Possibilities for methanogenic life in liquid methane on the surface of Titan. Icarus 178, 274-276.

Meier, R., et al., 1998a. A determination of the $\mathrm{HDO} / \mathrm{H}_{2} \mathrm{O}$ ratio in comet C/1995 01 (Hale-Bopp). Science 279, 842-844.

Meier, R., Smith, B. A., Owen, T. C., Terrile, R. J., 2000. The surface of Titan from NICMOS observations with the Hubble Space Telescope. Icarus 145, 462-473.

Michael, M., Johnson, R. E., Leblanc, F., Liu, M., Luhmann, J. G., Shematovich, V. I., 2005. Ejection of nitrogen from Titan's atmosphere by magnetospheric ions and pick-up ions. Icarus 175, 263-267.

Michael, M., Johnson, R. E., 2006. Energy deposition of pickup ions and heating of Titan's atmosphere. Plan. Space Sci. 53, 1510-1514.

Mitchell, D. G., Brandt, P. C., Roelof, E. C., Dandouras, J., Krimigis, S. M., Mauk, B. H., 2005. Energetic neutral atom emissions from Titan interaction with Saturn's magnetosphere. Science 308, 989-992.

Mitri, Giuseppe, Showman, Adam P., Lunine, Jonathan I., Lorenz, Ralph D., 2007. Hydrocarbon lakes on Titan. Icarus 186, 385-394.

Molina-Cuberos, G. J., López-Moreno, J. J., Rodrigo, R., Lara, L. M., 1999a. Chemistry of the galactic cosmic ray induced ionosphere of Titan. J. Geophys. Res. 104, 21997-22024.

Molina-Cuberos, G. J., López-Moreno, J. J., Rodrigo, R., Lara, L. M., O’Brien, K., 1999b. Ionization by cosmic rays of the atmosphere of Titan. Plan. Space Sci. 47, 1347-1354.

Molina-Cuberos, G. J., López-Moreno, J. J., Rodrigo, R., 2000. Influence of electrophilic species on the lower ionosphere of Titan. Geophys. Res. Let. 27, 1351.

Molina-Cuberos, G. J., Lammer, H., Stumptner, W., Schwingenschuh, K., Rucker, H. O., LópezMoreno, J. J., Rodrigo, R., Tokano, T., 2001. Ionospheric layer induced by meteoric ionization in Titan's atmosphere. Plan. Space Sci. 49, 143-153.

Molina-Cuberos, G. J., Schwingenschuh, K., López-Moreno, J. J., Rodrigo, R., Lara, L. M., Anicich, V., 2002. Nitriles produced by ion chemistry in the lower ionosphere of Titan. J. Geophys. Res. (Planets) 107, 9-1.

Monks, P. S., Romani, P. N., Neshitt, F. L., Scanlon, M., Stief, L. J., 1993. The kinetics formation of nitrile compounds in the atmospheres of Titan and Neptune, Geophys. Res. 98, 17,115-17, 123.

Moore, P., Hardy, D. A., 1972. In: Challenge of the Stars, pp. 32-33. Mitchell Beazley Ltd.

Moreno, R., Marten, A., Hidayat, T., 2005. Interferometric measurements of zonal winds on Titan. Astron. Astrophys. 437, 319-328.

Morente, Juan A., Molina-Cuberos, Gregorio J., Portí, Jorge A., Schwingenschuh, Korand, Besser, Bruno P., 2003. A study of the propagation of electromagnetic waves in Titan's atmosphere with the TLM numerical method. Icarus 162, 374-384. 
Mori, K., Tsunemi, H., Katayama, H., Burrows, D. N., Garmire, G. P., Metzger, A. E., 2004. An X-ray measurement of Titan's atmospheric extent from its Transit of the Crab Nebula. Astrophys. J. 607, $1065-1069$.

Morrison, D., Owen, T., Soderblom, L. A., 1986. The satellites of Saturn. In: Satellites (Burns, J., Matthews, M. S., eds.), Univ. of Arizona Press.

Mousis, O., Gautier, D., Bockelée-Morvan, D., 2002a. An evolutionary turbulent model of Saturn's subnebula: Implications for the origin of the atmosphere of Titan. Icarus 156, 162-175.

Mousis, O., Gautier, D., Coustenis, A., 2002b. The D/H ratio in methane in Titan. Origin and history. Icarus 159, 156-169.

Mousis, O., 2004. An estimate of the D/H ratio in Jupiter and Saturn's regular icy satellites Implications for the Titan Huygens mission. Astron. Astrophys. 414, 1165-1168.

Muhleman, D. O., Berge, G. L., Clancy, R. T., 1984. Microwave measurements of carbon monoxide on Titan. Science 223, 393-396.

Muhleman, D. O., Grossman, A. W., Butler, B. J., Slade, M. A., 1990. Radar reflectivity of Titan. Science 248, 975-980.

Muhleman, D. O, Grossman, A. W., Butler, B. J., 1995. Radar investigation of Mars, Mercury, and Titan. Ann. Rev. Earth Planet. Sci. 23, 337-374.

Müller-Wodarg, I. C. F., Yelle, R. V., 2002. The effect of dynamics on the composition of Titan's upper atmosphere. Geophys. Res. Let. 29, 54-1.

Müller-Wodarg, I. C. F., Yelle, R. V., Mendillo, M. J., Aylward, A. D., 2003. On the global distribution of neutral gases in Titan's upper atmosphere and its effect on the thermal structure. J. Geophys. Res. 108, SIA 18-1.

Müller-Wodarg, I. C. F., Yelle, R. V., Borggren, N., Waite, J. H., 2006. Waves and horizontal structures in Titan's thermosphere. J. Geophys. Res. 111, CiteID A12315.

Mumma, M. J., Weissman, P. R., Stern, S. A., 1993. Comets and the Origin of the Solar System: Reading the Rosetta Stone. In: Protostars and Planets III. (Levy, Lunine, eds.), 1177-1252. University of Arizona Press.

Nagy, A. F., Cravens, T. E., 1998. Titan's ionosphere: A review. Plan. Space Sci. 46, 1149-1156.

Nagy, A. F., Liu, Y., Hansen, K. C., Kabin, K., Gombosi, T. I., Combi, M. R., DeZeeuw, D. L., Powell, K. G., Kliore, A. J., 2001. The interaction between the magnetosphere of Saturn and Titan's ionosphere. J. Geophys. Res. 106, 6151-6160.

Neff, J. S., Humm, D. C., Bergstralh, J. T., Cochran, A. L., Cochran, W. D., Barker, E. S., Tull, R. G., 1984. Absolute spectrophotometry of Titan, Uranus, and Neptune: 3,500-10,500 Angstroms. Icarus 60, 221-235.

Neff, J. S., Ellis, T. A., Apt, J., Bergstralh, J. T., 1985. Bolometric albedos of Titan, Uranus, and Neptune. Icarus 62, 425-432.

Negrão, A., Roos-Serote, M., Rannou, P., Rages, K., Lourenço, B., 2005. On the latitudinal distribution of Titan's haze at the Voyager epoch. Plan. Space Sci. 53, 526-534.

Negrão, A., Coustenis, A., Lellouch, E., Maillard, J.-P., Rannou, Combes, M., Schmitt, B., McKay, C. P., Boudon, V., 2006. Titan's surface albedo from near-infrared CFHT/FTS spectra: Modeling dependence on the methane absorption. Plan. Space Sci. 54, 1225-1246.

Negrão, A., Hirtzig, M., Coustenis, A., Gendron, E., Drossart, P., Rannou, Combes, M., Boudon, V., 2007. 2-micron spectroscopy of Huygens' landing site on Titan with VLT/NACO. J. Geophys. Res. Planets 112, E02S92.

Neish, C. D., Lorenz, R. D., O'Brien, D. P., and the Casini RADAR Team, 2006. The potential for prebiotic chemistry in the possible cryovolcanic dome Ganesa Macula on Titan. International J. Astrobiology 5, 57-65.

Nelson, R. M., Brown, R. H., Hapke, B. W., Smythe, W. D., Kamp, L., Boryta, M. D., Leader, F., Baines, K. H., Bellucci, G., Bibring, J.-P., Buratti, B. J., Capaccioni, F., Cerroni, P., Clark, R. N., Combes, M., Coradini, A., Cruikshank, D. P., Drossart, P., Formisano, V., Jaumann, R., Langevin, Y., Matson, D. L., McCord, T. B., Mennella, V., Nicholson, P. D., Sicardy, B., Sotin, C., 
2006. Photometric properties of Titan's surface from Cassini VIMS: Relevance to Titan's hemispherical albedo dichotomy and surface stability. Plan. Space Sci. 54, 1540-1551.

Neubauer, F. M., Backes, H., Dougherty, M. K., Wennmacher, A., Russell, C. T., Coates, A., Young, D., Achilleos, N., André, N., Arridge, C. S., Bertucci, C., Jones, G. H., Khurana, K. K., Knetter, T., Law, A., Lewis, G. R., Saur, J., 2006. Titan's near magnetotail from magnetic field and electron plasma observations and modeling: Cassini flybys TA, TB, and T3. J. Geophys. Res. 111, CiteID A10220.

Nickolaenko, A. P., Besser, B. P., Schwingenschuh, K., 2003. Model computations of Schumann resonance on Titan. Plan. Space Sci. 51, 853-862.

Niemann, H. B., Atreya, S. K., Bauer, S. J., Carignan, G. R., Demick, J. E., Frost, R. L., Gautier, D., Haberman, J. A., Harpold, D. N., Hunten, D. M., Israel, G., Lunine, J. I., Kasprzak, W. T., Owen, T. C., Paulkovich, M., Raulin, F., Raaen, E., Way, S. H., 2005. The abundances of constituents of Titan's atmosphere from the GCMS instrument on the Huygens probe. Nature 438, 779-784.

Nixon, C. A., Achterberg, R. K., Vinatier, S., Bézard, B., Coustenis, A., Teanby, N. A., de Kok, R., Romani, P. N., Jennings, D. E., Bjoraker, G. L., Flasar, F. M. 2007. The ${ }^{12} \mathrm{C} /{ }^{13} \mathrm{C}$ ratio in Titan hydrocarbons from Cassini/CIRS Infrared Spectra. Icarus, in press.

Noll, K. S., Geballe, T. R., Knacke, R. F., Pendleton, Y. J., Titan's $5 \mu \mathrm{m}$ spectral window: Carbon monoxide and the albedo of the surface. Icarus 126, 625-631, 1996.

Noll, K. S., Knacke, R. F., Titan: 1-5 mm photometry and spectrophotometry and a search for variability. Icarus 101, 272-281, 1993.

O'Brien, D. P., Lorenz, R. D., Lunine, J. I., 2005. Numerical calculations of the longevity of impact oases on Titan. Icarus 173, 243-253.

Ori, G. G., Marinangeli, L., Baliva, A., Bressan, M., Strom, R. G., 1998. Fluid dynamics of liquids on Titans surface. Plan. Space Sci. 46, 1417-1421.

Orton, G., 1992. Ground-based observations of Titan's thermal spectrum, In: Symposium on Titan, ESA-SP 338 (Kaldeich, B., ed.), 81-85.

Osegovic, J. P., Max, M. D., 2005. Compound clathrate hydrate on Titan's surface. J. Geophys. Res. 110, CiteID E08004.

Ostro, S. J., Campbell, D. B., Simpson, R. A., Hudson, R. S., Chandler, J. F., Rosema, K. D., Shapiro, I. I., Standish, E. M., Winkler, R., Yeomans, D. K., Velez, R., Goldstein, R. M., 1992. Europa, Ganymede and Callisto: New radar results from Arecibo and Goldstone. J. Geophys. Res. 97, 18,227-18,244.

Owen, T., 1982a. Titan. Scientific American, 76-85.

Owen, T., 1982b. The composition and origin of Titan's atmosphere. Planet. Space Sci. 30, 833-838.

Owen, T., Cess, R. D., 1975. Methane absorption in the visible spectra of the outer planets and Titan. Astrophys. J. 197, L37-L40.

Owen, T., Gautier, D., 1989. Titan: Some new results. Adv. Space Res. 9, 73-78.

Owen, T., Lutz, B. L., de Bergh, C., 1986. Deuterium in the outer Solar system: Evidence for two distinct reservoirs. Nature 320, 244-246.

Owen, T., Bar-Nun, A., 1995, Comets, impacts, and atmospheres. Icarus 116, 215-226.

Owen T. C., 2000a. On the origin of Titan's atmosphere. Plan. Space Sci. 48, 747-752.

Owen T., 2005. Planetary science: Huygens rediscovers Titan. Nature 438, 756-757.

Paillou, Ph., Crapeau, M., Elachi, Ch., Wall, S., Encrenaz, P., 2006. Models of synthetic aperture radar backscattering for bright flows and dark spots on Titan. J. Geophys. Res. 111, CiteID E11011.

Paubert, G., Gautier, D., Courtin, R., 1984. The millimeter spectrum of Titan: Detectability of HCN, $\mathrm{HC}_{3} \mathrm{~N}$ and $\mathrm{CH}_{3} \mathrm{CN}$ and the $\mathrm{CO}$ abundance. Icarus 60, 599-612.

Peale, S. J., Lassen, P., Reynolds, R. T., 1980. Tidal dissipation, orbital evolution and the nature of Saturn's inner satellites. Icarus 43, 65-72.

Penteado, P. F., Griffith, C. A., Greathouse, T. K., de Bergh, C., 2005. Measurements of CH3D and CH4 in Titan from infrared spectroscopy. Astrophys. J. 629, L53-L56. 
Penz, T., Lammer, H., Biernat, H. K., 2005. The influence of the solar particle and radiation environment on Titan's atmosphere evolution. Adv. Space Res. 36, 241-250.

Pérez-Ayúcar, M., Lorenz, R. D., Floury, N., Prieto-Cerdeira, R., Lebreton, J.-P., 2006. Bistatic observations of Titan's surface with the Huygens probe radio signal. J. Geophys. Res. 111, CiteID E07001.

Perron, J. T., de Pater, I., 2004. Dynamics of an ice continent on Titan. Geophys. Res. Let. 31, CiteID L17S04.

Perron, J. T., Lamb, M. P., Koven, C. D., Fung, I. Y., Yager, E., Ádámkovics, M., 2006. J. Geophys. Res. 111, CiteID E11001.

Pettengill, G., 1965. Lunar radar reflections, In: Solar System Radio Astronomy (Aarons, J., ed.), p. 355. Plenum Press, New York.

Petculescu, A., Lueptow, R. M., 2007. Atmospheric acoustics of Titan, Mars, Venus, and Earth. Icarus 186, 413-419.

Petrie, S., 2001. Hydrogen isocyanide, HNC: A key species in the chemistry of Titan's ionosphere? Icarus 151, 196-203.

Pétrie, S., 2004. Products of meteoric metal ion chemistry within planetary atmospheres. $1 \mathrm{Mg}^{+}$at Titan. Icarus 171, 199-209.

Pinto, J. P., Lunine, J. I., Kim, S. J., Yung, Y. L., 1986. D to H ratio and the origin and evolution of Titan's atmosphere. Nature 319, 388-390.

Plankensteiner, K., Reiner, H., Rode, B. M., Mikoviny, T., Wisthaler, A., H., Armin, M., Tilmann, D., Fischer, G., Lammer, H., Rucker, H. O., 2007. Discharge experiments simulating chemical evolution on the surface of Titan. Icarus 187, 616-619.

Podolak, M., Bar-Nun, A., Tvoy, N., Giver, L. P., 1984. Inhomogeneous models of Titan's aerosol distribution, Icarus 57, 72-82.

Pollack, J. B., Rages, K., Toon, O. B., Yung, Y. L., 1980. On the relationship between secular brightness changes of Titan and solar variability. Geophys. Res. Lett. 7, 829-832.

Pollack, J. B., Bodenheimer, P., 1989. Theories of the origin and evolution of the Giant Planets. In: Origin and Evolution of Planetary and Satellite Atmospheres (Atreya, Pollack, Matthews, eds.), 564-602. University of Arizona Press.

Porco, C. C., Baker, E., Barbara, J., Beurle, K., Brahic, A., Burns, J. A., Charnoz, S., Cooper, N., Dawson, D. D., Del Genio, A. D., Denk, T., Dones, L., Dyudina, U., Evans, M. W., Fussner, S., Giese, B., Grazier, K., Helfenstein, P., Ingersoll, A. P., Jacobson, R. A., Johnson, T. V., McEwen, A., Murray, C. D., Neukum, G., Owen, W. M., Perry, J., Roatsch, T., Spitale, J., Squyres, S., Thomas, P., Tiscareno, M., Turtle, E. P., Vasavada, A. R., Veverka, J., Wagner, R., West, R., 2005. Imaging of Titan from the Cassini spacecraft. Nature 434, 159-168.

Prinn, R. G., Fegley, B. Jr., 1981. Kinetic inhibition of $\mathrm{CO}$ and $\mathrm{N}_{2}$ reduction in circumplanetary nebulae -- Implications for satellite composition. Astrophys. J. 249, 308-317.

Prockter, L., 2005. Planetary science: Shades of Titan. Nature 435, 749-750.

Rages, K., Pollack, J. B., Smith, P. H., 1983. Size estimates of Titan's aerosols based on Voyager 1 high-phase-angle images. J. Geophys. Res. 88, 8721-8728.

Rages, K. A., Pollack, J. B., 1983. Vertical distribution of scattering hazes in Titan's upper atmosphere. Icarus 55, 50-62.

Rages, K., Pollack, J. B. 1980. Titan aerosols: Optical properties and vertical distribution, Icarus 41, 119-130.

Rannou, P., Cabane, M., Chassefière, E., 1993. Growth of aerosols in Titan's atmosphere and related time scales: A stochastic approach. Geophys. Res. Lett. 20, 967-970.

Rannou, P., Cabane, M., Chassefière, E., Botet, R., McKay, C. P., Courtin, R., 1995. Titan's geometric albedo: Role of the fractal structure of the aerosols. Icarus 118, 355-372.

Rannou, P., Cabane, M., Botet, R., Chassefière, E., 1997. A new interpretation of the scattered light at Titan's limb. J. Geophys. Res. 102, 10997-11013. 
Rannou, P., Ferrari, C., Rages, K., Roos-Serote, M., Cabane, M., 2000. Characterization of aerosols in the detached haze layer of Titan. Icarus 147, 267-281.

Rannou, P., Hourdin, F., McKay, C. P., 2002. A wind origin for Titan's haze structure. Nature 418, 853-856.

Rannou, P., McKay, C. P., Lorenz, R. D., 2003. A model of Titan's haze of fractal aerosols constrained by multiple observations. Plan. Space Sci. 51, 963-976.

Rannou, P., Hourdin, F., McKay, C. P., Luz, D., 2004. A coupled dynamics-microphysics model of Titan's atmosphere. Icarus 170, 443-462.

Rannou, P., Montmessin, F., Hourdin, F., Lebonnois, S., 2006. The latitudinal distribution of clouds on Titan. Science 311, 201-205.

Rappaport, N., Bertotti, B., Giampieri, G., Anderson, J. D., 1997. Doppler measurements of the quadrupole moments of Titan. Icarus 126, 313-323.

Raulin, F., 1987. Organic chemistry in the oceans of Titan. Adv. Space Res. 7, 571-581.

Raulin, F., 2007. Astrobiology and habitability of Titan. Space Sci. Rev., DOI: 10.1007/s11214-0069133-7.

Raulin, F., 2007. Question 2: Why an astrobiological study of Titan will help us understand the origin of life. In: Origins of Life and Evolution of Biospheres, DOI : 10.1007/s11084-0079077-2.

Raulin, F., Mourey, D., Toupance, G., 1982. Organic synthesis from CH4 - N2 atmospheres: Implications for Titan. Orig. Life 12, 267-279.

Raulin, F., Accaoui, B. Razaghi, A., Dang-Nhu, M., Coustenis, A., Gautier, D., 1990. Infrared spectra of gaseous organics: Application to the atmosphere of Titan. II C4 alkanenitriles and benzene. Spectrochimica Acta 46, 671-683.

Raulin, F., Bruston, P., Paillous, P., Sternberg, R., 1995. The low temperature organic chemistry of Titan's geofluid. Adv. Space Res. 15(3), 321-333.

Raulin, F., 2005. Exo-astrobiological aspects of Europa and Titan: From observations to speculations. Space Sci. Rev. 116, 471-487.

Redondo, P., Pauzat, F., Ellinger, Y., 2006. Theoretical survey of the NH+CH3 potential energy surface in relation to Titan atmospheric chemistry. Plan. Space Sci. 54, 181-187.

Rees, M. H., 1989. Physics and Chemistry of the Upper Atmosphere, Cambridge: Cambridge University Press.

Ricca, A., Bauschlicher, C. W., Bakes, E. L. O., 2002. A computational study of the mechanisms for the incorporation of a Nitrogen atom into polycyclic aromatic hydrocarbons in the Titan haze. Icarus 154, 516-521.

Richardson, J., Lorenz, R. D., McEwen, A., 2004. Titan's surface and rotation: New results from Voyager 1 images. Icarus 170, 113-124.

Rodriguez, S., Le Mouélic, S., Sotin, C., Clénet, H., Clark, R. N., Buratti, B., Brown, R. H., McCord, T. B., Nicholson, P. D., Baines, K. H., the VIMS Science Team, 2006. Cassini/VIMS hyperspectral observations of the HUYGENS landing site on Titan. Plan. Space Sci. 54, $1510-1523$.

Rodriguez, S., Paillou, P., Dobrijevic, M., Ruffié, G., Coll, P., Bernard, J. M., Encrenaz, P., 2003. Impact of aerosols present in Titan's atmosphere on the CASSINI radar experiment. Icarus 164, 213-227.

Roe, H. G., de Pater, I., Macintosh, B. A., Gibbard, S. G., Max, C. E., McKay, C. P., 2002a. Titan's atmosphere in late southern spring observed with adaptive optics on the W. M. Keck II 10-Meter Telescope. Icarus 157, 254-258.

Roe, H. G., de Pater, I., Macintosh, B. A., McKay, C. P., 2002b. Titan's clouds from Gemini and Keck adaptive optics imaging. Astrophys. J. 581, 1399-1406.

Roe, H. G., Greathouse, T. K., Richter, M. J., Lacy, J. H., 2003. Propane on Titan. Astrophys. J. 597, L65-L68. 
Roe, H. G., de Pater, I., Gibbard, S. G., Macintosh, B. A., Max, C. E., Young, E. F., Brown, M. E., Bouchez, A. H., 2004a. A new 1.6-micron map of Titan's surface. Geophys. Res. Let. 31, CiteID L17S03.

Roe, H. G., de Pater, I., McKay, C. P., 2004b. Seasonal variation of Titan's stratospheric ethylene observed. Icarus 169, 440-461.

Roe, H. G., Bouchez, A. H., Trujillo, C. A., Schaller, E. L., Brown, M. E., 2005a. Discovery of temperate latitude clouds on Titan. Astrophys. J. 618, L49-L52.

Roe, H. G., Brown, M. E., Schaller, E. L., Bouchez, A. H., Trujillo, C. A., 2005b. Geographic control of Titan's mid-latitude clouds. Science 310, 477-479.

Roos-Serote, M., 2005. The changing face of Titan's haze: Is it all dynamics? Space science reviews 116, 201-210.

Roush, T. L., Dalton, J. B., 2004. Reflectance spectra of hydrated Titan tholins at cryogenic temperatures and implications for compositional interpretation of red objects in the outer Solar System. Icarus 168, 158-162.

Saint-Pé, O., Combes, M., Rigaut, F., Tomasko, M., Fulchignoni, M., 1993. Demonstration of adaptive optics for resolved imagery of solar system objects: Preliminary results on Pallas and Titan. Icarus 105, 263-270.

Sagan, C., 1973. The greenhouse of Titan. Icarus 18, 649-656.

Sagan, C., Dermott, S. F., 1982. The tide in the seas of Titan. Nature 300, 731-733.

Sagan, C., Thompson, W. R., 1984. Production and condensation of organic gases in the atmosphere of Titan. Icarus 59, 133-161.

Sagan, C., Khare, B. N., Lewis, J. S., 1984. Organic matter in the Saturn system. In: Saturn (Gehrels, T. and M. S. Matthews, eds.), 788-807, Univ. Arizona Press, Tucson.

Sagan, C., Thompson, W. R., Khare, B. N., 1992. Titan: A laboratory for prebiological organic chemistry. Accounts Chem. Res. 25, 286-292.

Salinas, S. V., Grieger, B., Markiewicz, W. J., Keller, H. U., 2003. A spherical model for computing polarized radiation in Titan's atmosphere. Plan. Space Sci. 51, 977-989.

Samuelson, R. E., Hanel, R. A., Kunde, V. G., Maguire, W. C., 1981. Mean molecular weight and hydrogen abundance of Titan's atmosphere. Nature 292, 688-693.

Samuelson, R. F., Maguire, W. C., Hand, R. A., Kunde, V. G., Jennings, D. F., Yung, Y. L., Aikin, A. C., 1983. $\mathrm{CO}_{2}$ on Titan, J. Geophys. Res. 88, 8709-8715.

Samuelson, R. F., Mayo, L. A., 1991. Thermal infrared properties of Titan's stratospheric aerosol, Icarus 91, 207-219.

Samuelson, R. E., Mayo, L. A., Knuckles, M. A., Khanna, R. J., 1997a. C $_{4} \mathrm{~N}_{2}$ ice in Titan's north polar stratosphere. Planet. Space Sci. 45, 941-948.

Samuelson, R. E., Mayo, L. A., 1997b. Steady-state model for methane condensation in Titan's troposphere. Planet. Space Sci. 45, 949-958.

Samuelson, R. E., Nath, N. R., Borysow, A., 1997c. Gaseous abundances and methane supersaturation in Titan's troposphere. Planet. Space Sci. 45, 959-980.

Samuelson, R. E., 2003. Titan's atmospheric engine: An overview. Planet. Space Sci. 51, 127-145.

Samuelson, R. E., Smith, M. D., Achterberg, R. K., Pearl, J. C., 2007. Cassini CIRS update on stratospheric ices at Titan's winter pole. Icarus 189, 63-71.

Scattergood, T. W, Lau, E. Y., Stone, B. M., 1992. Titan's aerosols. I. Laboratory investigations of shapes, size distributions, and aggregation of particles produced by UV photolysis of model Titan atmospheres. Icarus 99, 98-105.

Schaller, E. L., Brown, M. E., Roe, H. G., Bouchez, A. H., 2006. A large cloud outburst at Titan's south pole. Icarus 182, 224-229.

Schaller, E. L., Brown, M. E., Roe, H. G., Bouchez, A. H., Trujillo, C. A., 2006. Dissipation of Titan's south polar clouds. Icarus 184, 517-523.

Shemansky, D. E., Stewart, A. I. F., West, R. A., Esposito, L. W., Hallett, J. T., Liu, X., 2005. The Cassini UVIS Stellar Probe of the Titan atmosphere. Science 308, 978-982. 
Shematovich, V. I., Johnson, R. E., Michael, M., Luhmann, J. G., 2003. Nitrogen loss from Titan. J. Geophys. Res. 108, 6-1.

Schulze-Makuch, D., Grinspoon, D. H., 2005. Biologically enhanced energy and carbon cycling on Titan? Astrobiology 5, 560-567.

Sears, W. D., 1995. Tidal dissipation in oceans on Titan. Icarus 113, 39-56.

Seiff, A., Stoker, C. R., Young, R. E., Mihalov, J. D., McKay, C. P., Lorenz, R. D., 2005. Determination of physical properties of a planetary surface by measuring the deceleration of a probe upon impact: Application to Titan. Plan. Space Sci. 53, 594-600.

Sekine, Y., Sugita, S., Shido, T., Yamamoto, T., Iwasawa, Y., Kadono, T., Matsui, T., 2005. The role of Fischer Tropsch catalysis in the origin of methane-rich Titan. Icarus 178, 154-164.

Shindo, F., Benilan, Y., Guillemin, J.-C., Chaquin, P., Jolly, A., Raulin, F., 2003. Ultraviolet and infrared spectrum of $\mathrm{C} 6 \mathrm{H} 2$ revisited and vapor pressure curve in Titan's atmosphere. Plan. Space Sci. 51, 9-17.

Sicardy, B., Brahic, A., Ferrari, C., Gautier, D., Lecacheux, J., Lellouch, E., Roques, F., Arlot, J. E., Thuillot, W., Colas, F., Sevres, F., Vidal, J.-L., Blanco, C., Cristaldi, S., Buile, C., Klotz, A., Thouvenot, E., 1989. The July 3, 1989, occultation of 28 Sagitarii: Probing Titan's atmosphere. Nature 343, 350-353.

Sicardy, B., Colas, F., Widemann, T., Bellucci, A., Beisker, W., Kretlow, M., Ferri, F., Lacour, S., Lecacheux, J., Lellouch, E., Pau, S., Renner, S., Roques, F., Fienga, A., Etienne, C., Martinez, C., Glass, I. S., Baba, D., Nagayama, T., Nagata, T., Itting-Enke, S., Bath, K.-L., Bode, H.-J., Bode, F., Lüdemann, H., Lüdemann, J., Neubauer, D., Tegtmeier, A., Tegtmeier, C., Thomé, B., Hund, F., deWitt, C., Fraser, B., Jansen, A., Jones, T., Schoenau, P., Turk, C., Meintjies, P., Hernandez, M., Fiel, D., Frappa, E., Peyrot, A., Teng, J. P., Vignand, M., Hesler, G., Payet, T., Howell, R. R., Kidger, M., Ortiz, J. L., Naranjo, O., Rosenzweig, P., Rapaport, M., 2006. The two Titan stellar occultations of 14 November 2003. J. Geophys. Res. 111, CiteID E11S91.

Siegert, M. J., Hodgkins, R., 2000. A stratigraphic link across $1100 \mathrm{~km}$ of the Antarctic Ice Sheet between the Vostok ice-core site and Titan Dome (near South Pole). Geophys. Res. Let. 27, 2133-2136.

Sillanpää, I., Kallio, E., Janhunen, P., Schmidt, W., Mursula, K., Vilppola, J., Tanskanen, P., 2006. Hybrid simulation study of ion escape at Titan for different orbital positions. Adv. Space Res. 38, 799-805.

Sittler, E. C., Hartle, R. E., Viñas, A. F., Johnson, R. E., Smith, H. T., Mueller-Wodarg, I., 2005. Titan interaction with Saturn's magnetosphere: Voyager 1 results revisited. J. Geophys. Res. 110, CiteID A09302.

Smith, B. A., Soderblom, L., Batson, R., Bridges, P., Inge, J., Masursky, H., Shoemaker, E., Beebe, R., Boyce, J., Briggs, G., Buncer, A., Collins, S. A., Hansen, C. J., Johnson, T. V., Mitchell, J. L., Terrile, R. J., Cook Ii, A. F., Cuzzi, J., Pollack, J. P., Hunt, G. E., Danielson, G., Morrison, D., Owen, T., Sagan, C., Veverka, J., Strom, R., Suomi, V. E., 1982. A new look at the Saturn system: The Voyager 2 images. Science 215, 504-537.

Smith, B. A., Soderblom, L., Beebe, R., Boyce, J., Briggs, G., Buncer, A., Collins, S. A., Hansen, C. J., Johnson, T. V., Mitchell, J. L., Terrile, R. J., Carr, M., Cook Ii, A. F., Cuzzi, J., Pollack, J. P., Danielson, G. E., Ingersoll, A., Davies, M. E., Hunt, G. E., Masursky, H., Shoemaker, E., Morrison, D., Owen, T., Sagan, C., Veverka, J., Strom, R., Suomi, V. E., 1981. Encounter with Saturn: Voyager 1 imaging science results. Science 212, 163-191.

Smith, G. R., Strobel, D. F., Broadfoot, A. L., Sandel, B. R. Shemansky, D. F., Holberg, J. B., 1982. Titan's upper atmosphere: Composition and temperature from the EUV solar occultation results, J. Geophys. Res. 87, 1351-1359.

Smith, H. T., Johnson, R. E., Shematovich, V. I., 2004. Titan's atomic and molecular nitrogen tori. Geophys. Res. Let. 31, CiteID L16804.

Smith, P. H., Lemmon, M. T., Lorenz, R. D., Sromovsky, L. A., Caldwell, J. J., Allison, M. D., 1996. Titan's surface revealed by HST imagery. Icarus 119, 336-349. 
Smyth, W. H., 1981. Titan's hydrogen torus, Astrophys. J. 246, 344-353.

Sohl, F., Sears, W. D., Lorenz, R. D., 1995. Tidal dissipation on Titan. Icarus 115, 278-294.

Sohl, F., Hussmann, H., Schwentker, B., Spohn, T., Lorenz, R. D., 2003. Interior structure models and tidal love numbers of Titan. J. Geophys. Res. 108, 4-1.

Sotin, C., Jaumann, R., Buratti, B. J., Brown, R. H., Clark, R. N., Soderblom, L. A., Baines, K. H., Bellucci, G., Bibring, J.-P., Capaccioni, F., Cerroni, P., Combes, M., Coradini, A., Cruikshank, D. P., Drossart, P., Formisano, V., Langevin, Y., Matson, D. L., McCord, T. B., Nelson, R. M., Nicholson, P. D., Sicardy, B., Lemouelic, S., Rodriguez, S., Stephan, K., Scholz, C. K., 2005. Release of volatiles from a possible cryovolcano from near-infrared imaging of Titan. Nature 435, 786-789.

Sotin, C., 2007. Titan's lost seas found. Nature 445, 29-30.

Spilker, T. R., Significant science at Titan and Neptune from aerocaptured missions. Plan. Space Sci. 53, 606-616.

Sromovsky, L. A., Suomi, V. E., Pollack, J. B., Krauss, R. J., Limaye. S.S, Owen, T., Revercomb, H. E., Sagan, C., 1981. Implications of Titan's north south brightness asymmetry. Nature 292, 698-702.

Stahl, F., Schleyer, P. V. R., Schaefer, H. F., III, Kaiser, R. I., 2002. Reactions of ethynyl radicals as a source of C4 and C5 hydrocarbons in Titan's atmosphere. Plan. Space Sci. 50, 685-692.

Steinfeld, J. I. 1985. Molecules and Radiation. MIT Press.

Stevens, Michael, H., 2001. The EUV airglow of Titan: Production and loss of $\mathrm{N}_{2} \mathrm{c}_{4}{ }_{4}(0)-\mathrm{X}$. J. Geophys. Res. 106, 3685-3690.

Stevenson, D. J., 1992. Interior of Titan. In: Symposium on Titan, ESA-SP 338 (Kaldeich, B., ed.), 29-33.

Stevenson, D. J., Harris, A. W., Lunine, J. I., 1986. Origins of satellites. In: Satellites (Burns, J. A. and Matthews, M. S. Eds.), 39-88, University of Arizona Press, Tucson.

Stevenson, D. J., Lunine, J. I., 1986a. Mobilisation of cryogenic ices in Outer Solar System satellites. Nature 323, 46-48.

Stevenson, D. J., Potter, B. E., 1986b. Titan's latitudinal temperature distribution and seasonal cycle. Geophys. Res. Lett. 17, 93-96.

Stofan, E. R., Lunine, J. I., Lopes, R., Paganelli, F., Lorenz, R. D., Wood, C. A., Kirk, R., Wall, S., Elachi, C., Soderblom, L. A., Ostro, S., Janssen, M., Radebaugh, J., Wye, L., Zebker, H., Anderson, Y., Allison, M., Boehmer, R., Callahan, P., Encrenaz, P., Flamini, E., Francescetti, G., Gim, Y., Hamilton, G., Hensley, S., Johnson, W. T. K., Kelleher, K., Muhleman, D., Picardi, G., Posa, F., Roth, L., Seu, R., Shaffer, S., Stiles, B., Vetrella, S., West, R., 2006. Mapping of Titan: Results from the first Titan radar passes. Icarus 185, 443-456.

Stofan, E. R., Elachi, C., Lunine, J. I., Lorenz, R. D., Stiles, B., Mitchell, K. L., Ostro, S., Soderblom, L., Wood, C., Zebker, H., Wall, S., Janssen, M., Kirk, R., Lopes, R., Paganelli, F., Radebaugh, J., Wye, L., Anderson, Y., Allison, M., Boehmer, R., Callahan, P., Encrenaz, P., Flamini, E., Francescetti, G., Gim, Y., Hamilton, G., Hensley, S., Johnson, W. T. K., Kelleher, K., Muhleman, D., Paillou, P., Picardi, G., Posa, F., Roth, L., Seu, R., Shaffer, S., Vetrella, S., West, R., 2007. The lakes of Titan. Nature 445, 61-64.

Strobel, D. F., 1974. The photochemistry of hydrocarbons in the atmosphere of Titan, Icarus 21, 466-470.

Strobel, D. F., 1982. Chemistry and evolution of Titan's atmosphere. Planet. Space Sci. 30, 839-848.

Strobel, D. F., 1985. The photochemistry of hydrocarbons in the atmosphere of Titan. In: The atmospheres of Saturn and Titan, Proc. Int. Workshop, Alpbach, Austria, 16-19 September 1985, ESA SP-241.

Strobel, D. F., 2005. Photochemistry in outer solar system atmospheres. Space Sci. Rev. 116, $155-170$.

Strobel, D. F., Summers, M. F., Zhu, X., 1992. Titan's upper atmosphere: Structure and ultraviolet emissions, Icarus 100, 512-526. 
Strobel, D. F., Hall, D. T., Zhu, X., Summers, M. F., 1993. Upper limit on Titan's atmospheric argon abundance. Icarus 103, 333-336.

Strobel, D. F., 2006. Gravitational tidal waves in Titan's upper atmosphere. Icarus 182, 251-258.

Sultan-Salem, A. K., Tyler, G. L., 2007. Revisiting Titan's Earth-based scattering data at $13 \mathrm{~cm}-\lambda$. Geophys. Res. Let. 34, doi: 10.1029/2007GL029928.

Sultan-Salem, A. K., Tyler, G. L., 2007. Modeling quasi-specular scattering from the surface of Titan. J. Geophys. Res. 112, CiteID E05012.

Szego, K., Bebesi, Z., Erdos, G., Foldy, L., Crary, F., McComas, D. J., Young, D. T., Bolton, S., Coates, A. J., Rymer, A. M., Hartle, R. E., Sittler, E. C., Reisenfeld, D., Bethelier, J. J., Johnson, R. E., Smith, H. T., Hill, T. W., Vilppola, J., Steinberg, J., Andre, N., 2005. The global plasma environment of Titan as observed by Cassini Plasma Spectrometer during the first two close encounters with Titan. Geophys. Res. Let. 32, CiteID L20S05.

Szopa, C., Cernogora, G., Boufendi, L., Correia, J. J., Coll, P., 2006. PAMPRE: A dusty plasma experiment for Titan's tholins production and study. Plan. Space Sci. 54, 394-404.

Tanguy, L., Bézard, B., Marten, A., Gautier, D., Gérard, E., Paubert, G., Lecacheux, A., 1990. Stratospheric profile of $\mathrm{HCN}$ on Titan from millimeter observations. Icarus 85, 43-57.

Taylor, F. W., 1972. Temperature sounding experiments for the Jovian planets. J. Atmos. Sci. 29, 950-958.

Taylor, F. W., S. B. Calcutt, P. G. J., Irwin, C. A., Nixon, P. L., Read, P. J. C., Smith, T. J., 1998. Vellacott. Investigation of Saturn's atmosphere by CASSINI. Plan. Space Sci. 46, $1315-1324$.

Taylor, F. W., 2006. Climate variability on Venus and Titan. Space Sci. Rev. 125, 445-455.

Taylor, F. W., Coustenis, A., 1998. Titan in the Solar system. Planet. Space Sci. 46, 1085-1098.

Teanby, N. A., Irwin, P. G. J., de Kok, R., Nixon, C. A., Coustenis, A., Bézard, B., Calcutt, S. B., Bowles, N. E., Flasar, F. M., Fletcher, L., Howett, C., Taylor F. W., 2006. Latitudinal variations of $\mathrm{HCN}, \mathrm{HC}_{3} \mathrm{~N}$ and $\mathrm{C}_{2} \mathrm{~N}_{2}$ in Titan's stratosphere derived from Cassini CIRS data. Icarus 181, 243-255.

Teanby, N. A., Irwin, P. G. J., de Kok, R., Vinatier, S., Bézard, B., Nixon, C. A., Flasar, F. M., Calcutt, S. B., Bowles, N. E., Fletcher, L., Howett, C., Taylor, F. W., 2007. Vertical profiles of $\mathrm{HCN}, \mathrm{HC}_{3} \mathrm{~N}$, and $\mathrm{C}_{2} \mathrm{H}_{2}$ in Titan's atmosphere derived from Cassini/CIRS data. Icarus 186, 364-384.

Teanby, N. A., Irwin, P. G. J., de Kok, R., Nixon, C. A., Coustenis, A., Calcutt, S. B., Bowles, N. E., Fletcher, L., Howett, C., Taylor, F. W., 2007. Global variations of $\mathrm{C}_{2} \mathrm{H}_{2}, \mathrm{C}_{3} \mathrm{H}_{4}, \mathrm{C}_{4} \mathrm{H}_{2}, \mathrm{HCN}$ and $\mathrm{HC}_{3} \mathrm{~N}$ in Titan's stratosphere for early northern winter. Submitted to Icarus.

The Cassini Vims Team, Hansen, G. B., Buratti, B. J., Clark, R. N., Cruikshank, D. P., D’Aversa, E., Griffith, C. A., Baines, E. K. H., Brown, R. H., Dalle Ore, C. M., Filacchione, G., Formisano, V., Hibbitts, C. A., Jaumann, R., Lunine, J. I., Nelson, R. M., Sotin, C., 2006. Composition of Titan's surface from Cassini VIMS. Plan. Space Sci. 54, 1524-1539.

The Vims Science Team, Le Mouélic, S., Sotin, C., Clénet, H., Clark, R. N., Buratti, B., Brown, R. H., McCord, T. B., Nicholson, P. D., Baines, K. H., 2006. Cassini/VIMS hyperspectral observations of the HUYGENS landing site on Titan. Plan. Space Sci. 54, 1510-1523.

Thomas-Osip, J. E., Gustafson, B. Å. S., Kolokolova, L., Xu, Y.-L., 2005. An investigation of Titan's aerosols using microwave analog measurements and radiative transfer modelling. Icarus 179, 511-522.

Thompson, W. R., Sagan, C., 1984. Titan: Far-infrared and microwave remote sensing of methane clouds and organic haze. Icarus 60, 236-259.

Thompson, W. R., Sagan, C., 1991. Plasma discharge in $\mathrm{N}_{2}+\mathrm{CH}_{4}$ at low pressures: Experimental results and applications to Titan. Icarus 90, 57-73.

Tobie, G., Grasset, O., Lunine, J. I., Mocquet, A., Sotin, C., 2005a. Titan's internal structure inferred from a coupled thermal-orbital model. Icarus 175, 496-502. 
Tobie, G., Mocquet, A., Sotin, C., 2005b. Tidal dissipation within large icy satellites: Applications to Europa and Titan. Icarus 177, 534-549.

Tobie, G., Lunine, J. I., Sotin, C., 2006. Episodic outgassing as the origin of atmospheric methane on Titan. Nature 440, 61-64.

Tokano, T., 2005. Meteorological assessment of the surface temperatures on Titan: Constraints on the surface type. Icarus 173, 222-242.

Tokano, T., Neubauer, F. M., Laube, M., McKay, C. P., 1999. Seasonal variation of Titan's atmospheric structure simulated by a general circulation model. Planet. Space Sci. 47, 493-520.

Tokano, T., Molina-Cuberos, G. J., Lammer, H., Stumptner, W., 2001a. Modelling of thunderclouds and lightning generation on Titan. Plan. Space Sci. 49, 539-560.

Tokano, T., Neubauer, F. M., Laube, M., McKay, C. P., 2001b. Three-dimensional modeling of the tropospheric methane cycle on Titan. Icarus 153, 130-147.

Tokano, T., Neubauer, F. M., 2002. Tidal winds on Titan caused by Saturn. Icarus 158, 499-515.

Tokano, T., Neubauer, F. M., 2005. Wind-induced seasonal angular momentum exchange at Titan's surface and its influence on Titan's length-of-day. Geophys. Res. Lett. 32, CiteID L24203.

Tokano, T., Ferri, F., Colombatti, G., Mäkinen, T., Fulchignoni, M., 2006. Titan's planetary boundary layer structure at the Huygens landing site. J. Geophys. Res. 111, CiteID E08007.

Tokano, T., Lorenz, R. D., 2006. GCM simulation of balloon trajectories on Titan. Plan. Space Sci. 54, 685-694.

Tokano, T., McKay, C. P., Neubauer, F. M., Atreya, S. K., Ferri, F., Fulchignoni, M., Niemann, H. B., 2006. Methane drizzle on Titan. Nature 442, 432-435.

Tomasko, M., Smith, P. H., Photometry and polarimetry of Titan: Pioneer 11 observations and their implications for aerosol properties. Icarus 51, 65-95, 1982.

Tomasko, M. G., West, R. A., Orton, G. S., Tejfel, V. G., 1984. Clouds and aerosols in Saturn's atmosphere. In: Saturn (Gehrels, Matthews, eds.), Univ. of Arizona Press.

Toon, O. B., Turco, R. P., Pollack, J. B., 1980. A physical model of Titan's clouds. Icarus 43, 260-282.

Toon, O. B., McKay, C. P., Courtin, R., Ackerman, T., 1988. Methane rain on Titan, Icarus 75, 255-284.

Toon, O. B., McKay, C. P., Griffith, C. A., Turco, R. P., 1992. A physical model of Titan's aerosols. Icarus 95, 24-53.

Toublanc, D., Parisot, P., Brillet, J., Gautier, D., Raulin, F., McKay, C. P., 1995. Photochemical modelling of Titan's atmosphere. Icarus 113, 2-16.

Towner, M. C., Garry, J. R. C., Lorenz, R. D., Hagermann, A., Hathi, B., Svedhem, H., Clark, B. C., Leese, M. R., Zarnecki, J. C., 2006. Physical properties of Titan's surface at the Huygens landing site from the Surface Science Package Acoustic Properties sensor (API-S). Icarus 185, 457-465.

Tracadas, P. W., Hammel, H. B., Thomas-Osip, J. E., Elliot, J. L., Olkin, C. B., 2001. Probing Titan's atmosphere with the 1995 August Stellar Occultation. Icarus 153, 285-294.

Trafton, L., 1972. The bulk composition of Titan's atmosphere. Astrophys. J. 175, 295-306.

Trainer, M. G., Pavlov, A. A., Jimenez, J. L., McKay, C. P., Worsnop, D. R., Toon, O. B., Tolbert, M. A., 2004. Chemical composition of Titan's haze: Are PAHs present? Geophys. Res. Let. 31, CiteID L17S08.

Tran, Buu N., Ferris, James P., Chera, John J., 2003a. The photochemical formation of a titan haze analog. Structural analysis by x-ray photoelectron and infrared spectroscopy. Icarus 162, $114-124$.

Tran, B. N., Joseph, J. C., Ferris, J. P., Persans, P. D., Chera, J. J., 2003b. Simulation of Titan haze formation using a photochemical flow reactor: The optical constants of the polymer. Icarus $\mathbf{1 6 5}$, 379-390.

Tran, B. N., Joseph, J. C., Force, M., Briggs, R. G., Vuitton, V., Ferris, J. P., 2005. Photochemical processes on Titan: Irradiation of mixtures of gases that simulate Titan's atmosphere. Icarus 177, $106-115$. 
Tyler, G. L., Eshleman, V. R., Anderson, J. D., Levy, G. S., Lindal, G. F., Wood, G. E., Croft, T. A., 1981. Radio science investigations of the Saturn System with Voyager 1. Preliminary results. Science 212, 201-205.

Vacher, J. R., Le Duc, E., Fitaire, M., 2000. Clustering reactions of $\mathrm{HCNH}^{+}, \mathrm{HCNH}^{+}\left(\mathrm{N}_{2}\right)$ and $\mathrm{HCNH}^{+}\left(\mathrm{CH}_{4}\right)$ with ethane: Application to Titan atmosphere. Plan. Space Sci. 48, 237-247.

Vervack, R. J., Sandel, B. R., Strobel, D. F., 2004. New perspectives on Titan's upper atmosphere from a reanalysis of the Voyager 1 UVS solar occultations. Icarus 170, 91-112.

Veverka, J. Titan: Polarimetric evidence for an optically thick atmosphere. Icarus 18, 657-660, 1973.

Vinatier, S., Bézard, B., Fouchet, T., Teanby, N. A., de Kok, R., Irwin, P. G. J., Conrath, B. J., Nixon, C. A., Romani, P. N., Flasar, F. M., Coustenis, A., 2006. Vertical abundance profiles of hydrocarbons in Titan's atmosphere at $15^{\circ} \mathrm{S}$ and $80^{\circ} \mathrm{N}$ retrieved from Cassini/CIRS spectra. Icarus 188, 120-138.

Voss, L. F., Henson, B. F., Robinson, J. M., 2007. Methane thermodynamics in nanoporous ice: A new methane reservoir on Titan. J. Geophys. Res. 112, CiteID E05002.

Vuitton, V., Gée, C., Raulin, F., Bénilan, Y., Crépin, C., Gazeau, M.-C., 2003. Intrinsic lifetime of metastable excited $\mathrm{C}_{4} \mathrm{H}_{2}$ : Implications for the photochemistry of $\mathrm{C}_{4} \mathrm{H}_{2}$ in Titan's atmosphere. Plan. Space Sci. 51, 847-852.

Vuitton, V., Doussin, J.-F., Bénilan, Y., Raulin, F., Gazeau, M.-C., 2006a. Experimental and theoretical study of hydrocarbon photochemistry applied to Titan stratosphere. Icarus 185, 287-300.

Vuitton, V., Yelle, R. V., Anicich, V. G., 2006b. The nitrogen chemistry of Titan's upper atmosphere revealed. Astrophys. J. 647, L175-L178.

Wahlund, J.-E., Boström, R., Gustafsson, G., Gurnett, D. A., Kurth, W. S., Pedersen, A., Averkamp, T. F., Hospodarsky, G. B., Persoon, A. M., Canu, P., Neubauer, F. M., Dougherty, M. K., Eriksson, A. I., Morooka, M. W., Gill, R., André, M., Eliasson, L., Müller-Wodarg, I., 2005. Cassini measurements of cold plasma in the ionosphere of Titan. Science 308, 986-989.

Waite, J. H., Niemann, H., Yelle, R. V., Kasprzak, W. T., Cravens, Th. E., Luhmann, J. G., McNutt, R. L., Ip, W.-H., Gell, D., De La Haye, V., Müller-Wordag, I., Magee, B., Borggren, N., Ledvina, S., Fletcher, G., Walter, E., Miller, R., Scherer, S., Thorpe, R., Xu, J., Block, B., Arnett, K., 2005. Ion neutral mass spectrometer results from the first flyby of Titan. Science 308, 982-986.

Waite, J. H., Young, D. T., Cravens, T. E., Coates, A. J., Crary, F. J., Magee, B., Westlake, J., 2007. The process of tholin formation in Titan's upper atmosphere. Science 316, 870-875.

Walterscheid, R. L., Schubert, G., 2006. A tidal explanation for the Titan haze layers. Icarus 183, 471-478.

Wayne, R. P., 1985. Chemistry of Atmospheres, Oxford: Clarendon Press.

West, R. A., 1991. Optical properties of aggregate particles whose outer diameter is comparable to the wavelength. Appl. Opt. 30, 5316-5324.

West, R. A., Lane, A. L., Hart, H., Simmons, K. E., Hord, C. W., Coffeen, D. L., Esposito, L. W., Sato, M., Pomphrey, R. B., 1983. Voyager 2 photopolarimeter observations of Titan. J. Quant. Spectrosc. Radiat. Transfer 88, 8699-8708.

West, R. A., Smith, P. H., 1991. Evidence for aggregate particles in the atmospheres of Titan and Jupiter. Icarus 90, 330-333.

West, R. A., Brown, M. E., Salinas, S. V., Bouchez, A. H., Roe, H. G., 2005. No oceans on Titan from the absence of a near-infrared specular reflection. Nature 436, 670-672.

Whitten, R. C., Borucki, W. J., Tripathi, S., 2007. Predictions of the electrical conductivity and charging of the aerosols in Titan's nighttime atmosphere. J. Geophys. Res. 112, CiteID E04001.

Wilson, E. H., Atreya, S. K., 2000. Sensitivity studies of methane photolysis and its impact on hydrocarbon chemistry in the atmosphere of Titan? J. Geophys. Res. 105, 20,263-20,274.

Wilson, E. H., Atreya, S. K., Coustenis, A., 2003a. Mechanisms for the formation of benzene in the atmosphere of Titan. J. Geophys. Res. - Planets 108(E2), 5014-5024.

Wilson, E. H., Atreya, S. K., 2003b. Chemical sources of haze formation in Titan's atmosphere. Plan. Space Sci. 51, 1017-1033. 
Wilson, E. H., Atreya, S. K., 2004. Current state of modeling the photochemistry of Titan's mutually dependent atmosphere and ionosphere. J. Geophys. Res. 109, CiteID E06002.

Witasse, O., Lebreton, J.-P., Bird, M. K., Dutta-Roy, R., Folkner, W. M., Preston, R. A., Asmar, S. W., Gurvits, L. I., Pogrebenko, S. V., Avruch, I. M., Campbell, R. M., Bignall, H. E., Garrett, M. A., van Langevelde, H. Jan, Parsley, S. M., Reynolds, C., Szomoru, A., Reynolds, J. E., Phillips, C. J., Sault, R. J., Tzioumis, A. K., Ghigo, F., Langston, G., Brisken, W., Romney, J. D., Mujunen, A., Ritakari, J., Tingay, S. J., Dodson, R. G., van’t Klooster, C. G. M., Blancquaert, T., Coustenis, A., Gendron, E., Sicardy, B., Hirtzig, M., Luz, D., Negrao, A., Kostiuk, T., Livengood, T. A., Hartung, M., de Pater, I., Ádámkovics, M., Lorenz, R. D., Roe, H., Schaller, E., Brown, M., Bouchez, A. H., Trujillo, C. A., Buratti, B. J., Caillault, L., Magin, T., Bourdon, A., Laux, C., 2006. Overview of the coordinated ground-based observations of Titan during the Huygens mission. J. Geophys. Res. Planets 111, E07S01.

Wong, A., Morgan, C. G, Yung, Y. L., Owen, T. O., 2000. Evolution of CO on Titan. Icarus 155, 382-392.

Wye, L. C., Zebker, H. A., Ostro, S. J., West, R. D., Gim, Y., Lorenz, R. D., The Cassini Radar Team, 2007. Electrical properties of Titan's surface from Cassini RADAR scatterometer measurements. Icarus 188, 367-385.

Yelle, R. V., 1991. Non-LTE models of Titan's upper atmosphere, Astrophys. J. 383, 380-400.

Yelle, R. V., Griffith, C. A., 2003. HCN fluorescence on Titan. Icarus 166, 107-115.

Yelle, R. V., Borggren, N., de La Haye, V., Kasprzak, W. T., Niemann, H. B., Müller-Wodarg, I., Waite, J. H., 2006. The vertical structure of Titan's upper atmosphere from Cassini Ion Neutral Mass Spectrometer measurements. Icarus 182, 567-576.

Young, E. F., Rannou, P., McKay, C. P., Griffith, C. A., Noll, K., 2002. A three-dimensional map of Titan's tropospheric haze distribution based on Hubble Space Telescope Imaging. Astron. J. 123, 3473-3486.

Young, E. F., Puetter, R., Yahil, A., 2005. Direct imaging of Titan's extended haze layer from HST observations. Geophys. Res. Let. 31, L17S09.

Yung, Y. L., 1987. An update of nitrile photochemistry on Titan, Icarus 72, 468-472.

Yung, Y. L., Allen, M., Pinto, J. P., 1984. Photochemistry of the atmosphere of Titan: Comparison between model and observation. Astrophys. J. 55, 465-506.

Zahnle, K., Pollack, J. B., Grinspoon, D., Done, L., 1992. Impact generated atmospheres over Titan, Ganymede and Callisto. Icarus 95, 1-23.

Zarnecki, J. C., Leese, M. R., Hathi, B., Ball, A. J., Hagermann, A., Towner, M. C., Lorenz, R. D., McDonnell, J. A. M., Green, S. F., Patel, M. R., Ringrose, T. J., Rosenberg, P. D., Atkinson, K. R., Paton, M. D., Banaszkiewicz, M., Clark, B. C., Ferri, F., Fulchignoni, M., Ghafoor, N. A. L., Kargl, G., Svedhem, H., Delderfield, J., Grande, M., Parker, D. J., Challenor, P. G., Geake, J. E., 2005. A soft solid surface on Titan as revealed by the Huygens Surface Science Package. Nature 438, 792-795.

Zhu, X., Strobel, D. F., 2005. On the maintenance of thermal wind balance and equatorial superrotation in Titan's stratosphere. Icarus 176, 331-350.

Zhu, X., 2006. Maintenance of equatorial superrotation in the atmospheres of Venus and Titan. Plan. Space Sci. 54, 761-773. 
Acetylene $\left(\mathrm{C}_{2} \mathrm{H}_{2}\right), 14,27-30,32,55,98,152$, 162-164, 175-178, 185-188, 300

Aerosol composition, 14, 100-101, 104-105, 193, 213-221

Ammonia $\left(\mathrm{NH}_{3}\right), 5,15,286,300$

Argon, 5, 23, 155, 262, 322, 326

Ariel (satellite of Uranus), 1

Benzene $\left(\mathrm{C}_{6} \mathrm{H}_{6}\right), 43,98,152,158-159,163$, 165

Callisto (satellite of Jupiter), 1, 63, 286

Carbon dioxide $\left(\mathrm{CO}_{2}\right), 22,29,158,169$

Carbon monoxide (CO), 29, 159, 171-173, 189-192

Cassini, Giovanni Domenico, 1-2, 6-7

Cassini (spacecraft), 22, 53, 71-116, 130, 135-136, 141, 145, 149-150, 152, 155-160, 163-166, 172, 176-177, 179-183, 197-212, $230,238,241,246,251-252,254$

Climate, 129, 147-149

Cloud and haze, 20, 32-35, 52, 153, 192-230

Composite Infrared Spectrometer (CIRS), 91-94, 141-144, 160, 168, 175-181

Condensate clouds, 206-210

Deuterated methane $\left(\mathrm{CH}_{3} \mathrm{D}\right), 14,29,159,161$, 173-175, 328

Dione (satellite of Saturn), 1, 2, 8, 311

Doppler wind experiment, 88, 103-104, 245, 249

Dunes, 236, 255, 272-279

Dynamics, 210-213, 231-250

Enceladus (satellite of Saturn), 1, 5, 8, 316-317, 332

Energy balance, 137, 139, 211

Ethane $\left(\mathrm{C}_{2} \mathrm{H}_{6}\right), 14,24,27-30,32,68,140$, $162,185,195,202,207-210,216,220-221$, 239, 295-296, 300

Ethylene $\left(\mathrm{C}_{2} \mathrm{H}_{4}\right), 14,28,68,98,145,152,158$, 160, 163-164, 178, 185-186, 300

Europa (satellite of Jupiter), 1, 315, 318
Fractal models for haze, 195-197, 223-228

Galileo Galilei, 1, 318

Galileo (spacecraft), 109, 174, 255, 285, 299, 302-303

Ganymede (satellite of Jupiter), 1-2, 36, 56, 58, 258, 285-286, 305

Ground-based observatories, 44-51, 71

Herschel, William, 1, 313-314

Herschel, John, 3, 5

Hubble Space Telescope (HST), 21, 39-40, 64-66

Hunten, Don, 15, 22

Huygens, Christiaan, 1-4, 6-7, 18

Huygens (spacecraft), 22, 65, 71-116, 256-257, 261-266

Hydrocarbons, 158-159, 161-166, 176-181, 185-188, 192, 246

Hydrogen $\left(\mathrm{H}_{2}\right), 14-15,25,29,98-99,140$, $147,152,155,163,172-174,325-329,333$

Hydrogen cyanide (HCN), 29-31, 144, 166

Hyperion (satellite of Saturn), 1, 8, 63, 111,316

Iapetus (satellite of Saturn), 1, 63, 308-310 Infrared Interferometer Spectrometer (IRIS), $22,25,30-31,158$

Infrared Space Observatory (ISO), 38, 41-44, 158

Io (satellite of Jupiter), 1, 235, 236, 288, 307, 318,322

Isotopic ratios, 78, 94, 105, 130, 164, 290, 299-300, 328-329, 331, 336

James Webb Space Telescope, 40-41

Jet Propulsion Laboratory (JPL), 17-18, 332

Jupiter, 1, 3, 5, 12, 14, 16-18, 36, 73, 79-80, $82,84,94,109,174,235,255,258,285$, 286, 288, 290, 297-304, 308, 317-318, 323, 330-331, 340

Jupiter Icy Moons Orbiter, 341 
Kuiper, Gerard, 13-14, 44

Lakes, 33, 37, 54, 68, 147, 175, 254, 258, 262, 265-266, 271-272, 275-277, 285, 292, 294, 296, 316, 334-337, 345-347

Life, 285, 329-330, 334-335

Lightning, 37, 78, 91, 95, 99, 105, 237, 255-257, 339

Magnetospheric measurements, 97-99, 112-113, 144-147

Mars, 9, 12, 288, 296-297

Mercury, 12, 287, 309, 310

Meridional circulation, 65, 178, 243-244

Methane $\left(\mathrm{CH}_{4}\right), 5,14-15,21-25,27-30$, 32-33, 37, 40, 44, 54-57, 59-62, 64-65, 67, 70-71, 96, 98, 103, 130, 133-135, 137, 139-142, 144-145, 147-156, 161, 172, 174-175, 190, 195-196, 199, 204-205, 207-211, 218, 220-223, 230, 235, 243, 248, 251-254, 256, 259-262, 264-265, 273-275, 277-278, 280, 282-285, 291-295, 299-300, $310,318,320-328,331,334$

Meteorology, 66, 231-232, 250-257

Mimas (satellite of Saturn), 1, 5, 311-315

Moon (satellite of Earth), 9-12, 23, 41, 56, 58, $89,281,287,290,307,309,310,313,316$, 318,341

Neon, 5, 105, 324, 331

Neptune, 1, 12, 18, 297-304

Nitriles, 22, 29, 158, 166-168, 176-181, 188-189

Nitrogen $\left(\mathrm{N}_{2}\right), 5,14-15,22-23,150-152,286$, 325-326

North-south asymmetry, 20-21, 64-65, 200, 206, 212, 244-245

Oberon (satellite of Uranus), 1

Oceans or Seas, 24, 54-57, 153-154, 259

Oxygen, 43, 99, 105, 153, 164, 169, 183, 189-192, 293, 325, 327-328

Photochemistry, 31-33, 54, 165, 181-185

Phoebe (satellite of Saturn), 317

Pioneer (spacecraft), 16-17

Pluto, 13, 286, 315, 318-321

Propane $\left(\mathrm{C}_{3} \mathrm{H}_{8}\right), 27-29,161$
Questions, outstanding, 36-37, 78, 229-230, 335-336

Radar observations, 54-57, 96, 261, 270, 272, 275-277, 279, 336

Rain, 24, 33-34, 37, 54, 71, 153, 190, 212, 252-254, 261, 269, 271, 273-274, 278, 293, 316, 329-330

Rhea (satellite of Saturn), 1, 8, 111, 310-311

Sagan, Carl, 16, 32-33, 193

Saturn, 1, 12, 107-109, 297-304

Snow, 33, 70, 106, 153, 263, 273

Solar and thermal radiation, 137

Solar system, 289-290

Sun, 8-9, 12, 25, 192, 198, 217, 235, 243, 275, 286, 289-292, 298-299, 323, 324, 329, 340-341

Surface and landscape, 35-37, 66-71, 258-280

Surface composition, 277-280

Tethys (satellite of Saturn), 1, 2, 8

Tholins, 33, 193, 217-223

Titan (satellite of Saturn)

albedo, 57-64

atmospheric composition, 28-31, 154, 159, 163-164

discovery, 2, 13

energy balance, 26

interior, 37, 281-285

ionosphere, 155

magnetic field, 145

mythology, 5

origin and evolution, 321-329

name, 4

physical data, 23

pressure profile, $129-131$

radius, $22-23$

surface temperature, 22

temperature profile, $23-28,53,131-144$

Titania (satellite of Uranus), 1

Titania (spacecraft), 341-343

Triton (satellite of Neptune), 1, 286, 315,

318-321, 331

Ultraviolet (UV) observations, 19-21, 25-28, 31-32, 94-95

Umbriel (satellite of Uranus), 1

Uranus, 1, 12, 18, 297-304 
Venus, 12, 287, 290-296

Visible and Infrared Mapping Spectrometer (VIMS), 53, 95, 172, 208, 261, 272, 274, 278-279, 313

Volcanism, 33, 57, 66, 148, 174, 208, 236, 262, 266, 271-274, 277, 282-283, 285, 288, 294, $296,307,317,322-323,327,336,345-346$

Vortex, polar, 245-247, 304

Voyager (spacecraft), 2, 13, 16-38, 42-43, 64-65, 73, 81, 93, 140, 150-152, 155, 158-162, 167-169, 176, 180-183, 206, 213, $224,232,239,248,255,309,310,318$
Water vapour, 43, 158, 171, 327-328

Water ice, 57, 60-64

Winds, 52-53, 78, 103-104, 231, 238-242

Xanadu, 68, 86, 232-234, 260-261, 266-267, 270

Xenon, 341-342

Yung, Yuk, 27, 146, 182-184, 224, 246

Zarnecki, John, 106, 263, 282

Zonal winds, 52-53, 233, 237-242 